Article

\title{
A Review and New Problems Discovery of Four Simple Decentralized Maximum Power Point Tracking Algorithms-Perturb and Observe, Incremental Conductance, Golden Section Search, and Newton's Quadratic Interpolation
}

\author{
Victor Andrean ${ }^{\dagger, \ddagger}$, Pei Cheng Chang $\ddagger$ and Kuo Lung Lian ${ }^{*}+\leftarrow$ \\ Department of Electrical Engineering, National Taiwan University of Science and Technology, 2F, EE, No. 43, \\ Sec. 4, Keelung Rd, Taipei 106, Taiwan; andreanvictor6374@gmail.com (V.A.); perry4545@gmail.com (P.C.C.) \\ * Correspondence: ryankuolian@gmail.com \\ † Current address: Electrical Engineering, National Taiwan University of Science and Technology, \\ Taipei City 10607, Taiwan. \\ $\ddagger$ These authors contributed equally to this work.
}

Received: 22 September 2018; Accepted: 24 October 2018; Published: 1 November 2018

\begin{abstract}
Maximum Power Point Tracking (MPPT) enables photovoltaic (PV) systems to extract as much solar energy as possible. Depending on which type of controller is used, PV systems can be classified as centralized MPPT (CMPPT) or decentralized MPPT (DMPPT). In substring-level systems, it is known that the energy yield of DMPPT can outweigh the power electronics cost. At the substring level, it is usually assumed that the PV curve exhibits a single peak, even under partial shading. Thus, the control algorithms for DMPPT are usually less complicated than those employed in CMPPT systems. This paper provides a comprehensive review of four simple DMPPT algorithms, which are perturb and observe ( $\mathrm{P} \& \mathrm{O})$, incremental conductance (INC), golden section search (GSS), and Newton's quadratic interpolation (NQI). The comparison of these algorithms are done from the perspective of numerical analysis. Guidelines on how to set initial conditions and convergence criteria are thoroughly explained. This is of great interest to PV engineers when selecting algorithms for use in MPPT implementations. In addition, various problems that have never previously been identified before are highlighted and discussed. For instance, the problems of NQI trap is identified and methods on how to mitigate it are also discussed. All the algorithms are tested under various conditions including static, dynamic, and rapid changes of irradiance. Both simulation and experimental results indicate that $\mathrm{P} \& \mathrm{O}$ and INC are the best algorithms for DMPPT.
\end{abstract}

Keywords: decentralized maximum power point tracking; perturb and observe (P\&O); incremental conductance (INC); golden section search (GSS); Newton's quadratic interpolation (NQI)

\section{Introduction}

The increasing global demand for energy and growth in fossil fuel prices have led to something of an energy crisis in recent years [1,2]. Conventional energy sources, which generally use fossil fuels, produce significant carbon emissions. In confronting this issue, renewable and clean energy have become viable solutions.

Solar energy can be harnessed by photovoltaic generators (PVGs). Unlike wind turbines (WTs), PVGs have no moving parts, making them more environmentally friendly. Moreover, PVGs have lower investment and maintenance costs than WTs, and require less space. 
The main issue in controlling PVGs is that their output power is highly dependent on solar irradiation and temperature [3]. Furthermore, intermittency and rapid changes in irradiation and temperature lead to variations in the PVG I-V curve over time. To minimize the investment cost and enhance the energy conversion efficiency, it is crucial to control PVGs so as to produce the maximum output power. Three commonly used solar PV architectures are shown in Figure 1. Figure 1a shows the conventional solar PV architecture, also known as the series-string architecture [4-7]. All PV modules are connected in series and have only a single optimizer. Under this connection mode, partial shading of a single module will lead to a reduction in the overall system output power, and the power-voltage $(\mathrm{P}-\mathrm{V})$ curve will exhibit multiple peaks. This scenario requires a centralized maximum power point tracking (CMPPT) controller to obtain the global maximum power point (GMPP). Figure $1 b, c$ shows the micro-inverter and micro-converter architectures, which require distributed maximum power point tracking (DMPPT) controllers. In these architectures, each PV module is locally controlled by its local optimizer. Unlike CMPPT, any partial shading that occurs in a single module will only affect the power output of that module [4]. However, the micro-inverter usually requires a large voltage transformation ratio because the voltage of each PV module tends to be much lower than the utility voltage. This can lead to low converter efficiency issues. To address this, the cascade DC-DC converter architecture in Figure 1c was proposed. A localized MPP tracker allows the system to perform independent optimization. The series connection enables each DC-DC converter to perform at a relatively low voltage transformation ratio. The micro-converter structure has gained popularity as the energy yield benefit outweighs the power electronics costs for a substring-level DMPPT system [8]. At the substring level, it is usually assumed that the $\mathrm{P}-\mathrm{V}$ curve exhibits a single peak, even under partial shading. Hence, it is generally not necessary to employ CMPPT algorithms designed for multiple-peak problems. Thus, this paper will not discuss any CMPPT algorithms that can potentially be used as DMPPT algorithms.

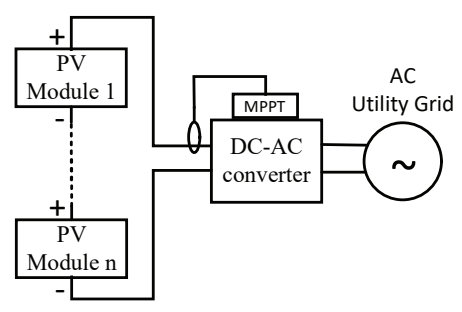

(a)

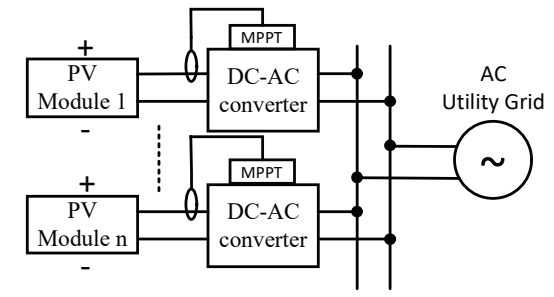

(b)

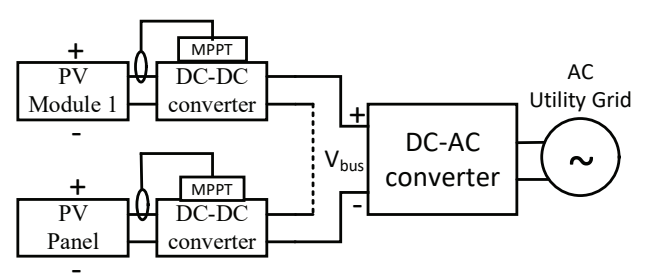

(c)

Figure 1. (a) series string architecture; (b) micro-inverter architecture; (c) DC-DC converter architecture.

Many DMPPT algorithms have been proposed in the literature. For example, Refs. [9-13] provide a comprehensive list of the published DMPPT algorithms. Generally, all these algorithms can be categorized into seven groups: cell-based methods (CBMs), perturbation-based methods (PBMs), conductance methods (CMs), interpolation-based methods (IBMs), bracketing-based methods (BBMs), root-finding methods (RFMs), and optimization-based methods (OBMs). CBMs, named by [10], operate using two important properties of PV cells, the open-circuit voltage (OCV) and the short-circuit current (SCC), and attempt to determine the relation between the MPP voltage $\left(V_{m p p}\right)$ and OCV (or between the MPP current, $I_{m p p}$, and SCC). CBMs include the fractional OCV method, where 
$V_{m p p}$ is simply assumed to be a fraction (usually $70-80 \%$ ) of the OCV, fractional SCC method, and modified fractional SCC method. PBMs can be further classified into natural perturbation and artificial perturbation methods. The former type includes the ripple correlation control method [14], which utilizes ripples in the current and voltage to track the MPP, whereas the latter defines a voltage or current perturbation to track the MPP, such as in the perturb-and-observe $(P \& O)$ method [15], hill-climbing method [16], estimated-perturb-perturb method [17], and modified perturb-and-observe method [18]. CMs employ the concept that the instantaneous conductance is equal to the incremental conductance at the MPP to track the maximum. Methods include incremental conduction (INC) [16], variable step-size INC [19], and sliding mode methods [20]. IBMs estimate the MPP using polynomial interpolation, and include Newton's quadratic interpolation (NQI) [21] and quadratic Lagrangian interpolation (QLI) [22]. BBMs determine successively smaller intervals (or brackets) that contain the MPP. Methods such as bisectional search [23], golden section search (GSS), and central point iteration methods [24] have been used to find the MPP. RFMs use root-finding techniques [25] such as Newton's method [3], the secant method [26], and steepest descent [27] to identify the MPP. Finally, OBMs recast the MPP search as an optimization problem to be solved using quadratic programming [28] or particle swarm optimization [29].

Some of these algorithms are very simple, such as the OCV methods. Although very fast, these estimate the MPP quite crudely. In contrast, some algorithms require more computation time to ensure the MPP is obtained. For instance, Ref. [28] designed an MPPT control technique that solves the Riccati equation, which involves extensive computations. In this paper, four DMPPT algorithms that lie between these two extremes are investigated. These algorithms are sufficiently accurate and require relatively few floating point operations (FLOPs). The chosen algorithms are $P \& O, I N C, G S S$, and NQI. These algorithms have a similar number of FLOPs per iteration cycle $(P \& O$, INC, and GSS have 11 FLOPs per iteration cycle, whereas NQI has 19 FLOPs per iteration cycle). Note that variants of these algorithms such as INC with variable time step and GSS combined with PSO [30] are not addressed in this paper. Moreover, all four algorithms update only one variable per iteration, which is simple to implement in a micro-controller. We believe that these four methods are of great interest to PV industrial engineers. Though $P \& O$ is believed to be the most widely used DMPPT algorithm, a thorough comparison has not been reported. Moreover, we will investigate each method from the viewpoint of numerical analysis. Generally, most MPPT algorithms have three steps: (1) initializing the unknown variables (i.e., the MPP voltage or current); (2) updating the unknown variables; and (3) checking the convergence criteria. Different algorithms tend to treat step 2 differently. However, steps 1 and 3 also play an important role in the tracking because different initial conditions and convergence criteria can affect the tracking speed and tracking accuracy. Therefore, in this paper, we compare these algorithms in terms of their initialization settings and convergence criteria. Hence, unlike previous review papers that only describe how MPPT methods work and infer general conclusions about those methods, this paper provides a comprehensive review and simulation-based validation of four MPPT methods. Moreover, new and important problems that have so far not been addressed are discussed, and mathematical descriptions are provided. The remainder of the paper is organized as follows: Section 2 provides a review of the four methods considered in this paper. Section 3 provides a thorough discussion of their initialization settings, convergence criteria, and updating steps. Finally, the conclusions to this study are presented in Section 4.

\section{Review of Various Methodologies}

This section briefly reviews the $P \& O$, INC, GSS, and NQI methods.

In this paper, the voltage is used as the control variable (CV), even though the duty-cycle can be used in a similar fashion. Current-based control implementation requires caution to prevent the PV current reaching its short-circuit current, Isc, resulting in a sudden voltage drop and power losses. 


\subsection{Perturb-and-Observe ( $P \& O)$}

The basic idea of the $P \& O$ method is to apply perturbation and observation alternately. The operating voltage $\left(V_{p v}\right)$ is perturbed by a small amount $\left(V_{c}\right)$ in every control cycle $\left(T_{\text {perb }}\right)$ to determine whether the algorithm is traveling up or down the $\mathrm{P}-\mathrm{V}$ curve. Figure 2 shows a flowchart of the $P \& O$ method. Depending on the sign of the differential changes in $V_{p v}$ and the PV power, $P_{p v}$, four different cases must be considered to determine whether $V_{p v}$ should be increased or decreased. For instance, when both $V_{p v}$ and $P_{p v}$ are increasing, $V_{c}$ is added to $V_{p v}$ to force the operating point to move towards the MPP.

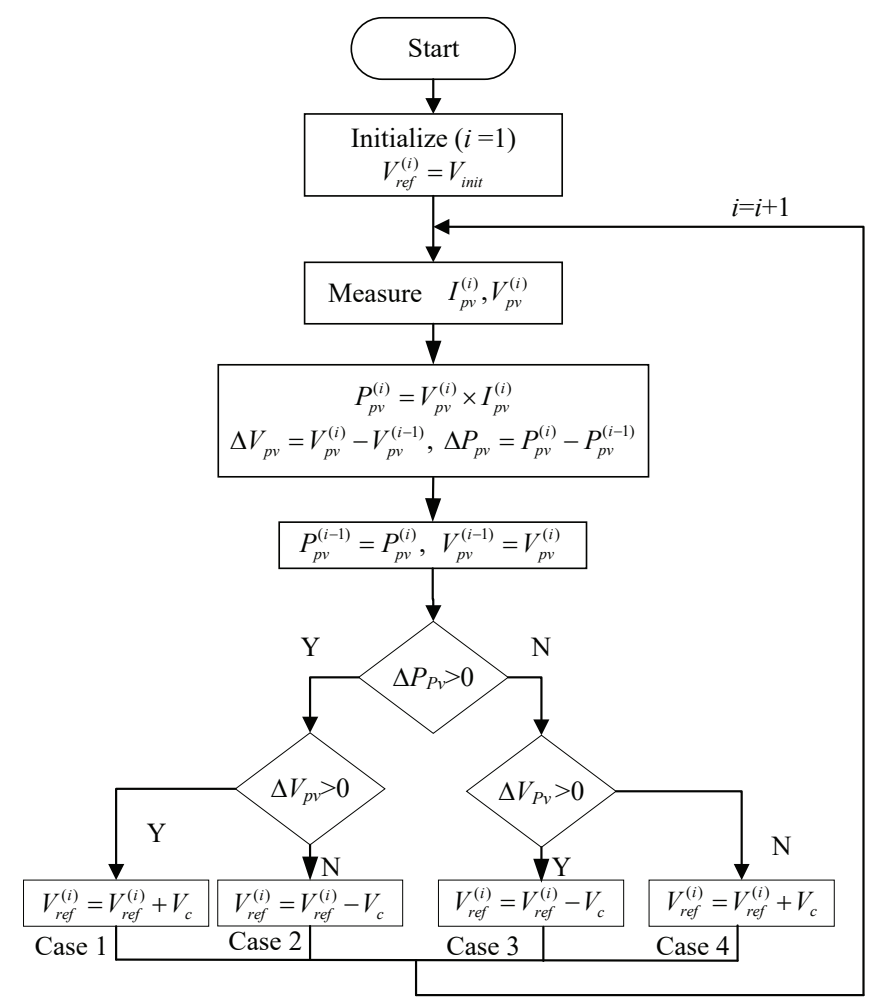

Figure 2. Flow chart of $P \& O$ method.

\subsection{Incremental Conductance}

This method exploits the assumption that the ratio of change in output conductance is equal to the negative output conductance, and is derived as follows:

$$
\begin{gathered}
\frac{d P_{p v}}{d V_{p v}}=\frac{d\left(V_{p v} I_{p v}\right)}{d V_{p v}}=0, \\
\frac{d P_{p v}}{d V_{p v}}=I_{p v}+V_{p v} \frac{d I_{p v}}{d V_{p v}}=0 .
\end{gathered}
$$

Thus, the MPP is reached when

$$
\frac{d I_{p v}}{d V_{p v}}=-\frac{I_{p v}}{V_{p v}} .
$$

Note that $\frac{I_{p v}}{V_{p v}}$ is considered to be the instantaneous conductance (IC), whereas $\frac{\Delta I_{p v}}{\Delta V_{p v}}$ is the incremental conductance (INC). The MPP is tracked by continuously comparing IC against INC. When the angle $\alpha=\beta$, as shown in Figure 3, the MPP is reached. As indicated in the figure, IC is always positive and INC is always negative.

Hence, there are only three cases to be considered when $\Delta V_{p v} \neq 0$ : 
1. when $\frac{d I}{d V}<-\frac{I}{V}$, the operating point is to the right of the MPP;

2. when $\frac{d I}{d V}=-\frac{I}{V}$, the operating point is at the MPP;

3. when $\frac{d I}{d V}>-\frac{I}{V}$, the operating point is to the left of the MPP.

This is illustrated in Figure 4. When there is a sudden change in irradiance, the voltage does not change instantaneously, and so $\Delta V_{p v}=0$. If the current change is positive, as shown in Figure 4, $V_{p v}$ needs to be reduced to bring the operating point towards the MPP, and vice versa.

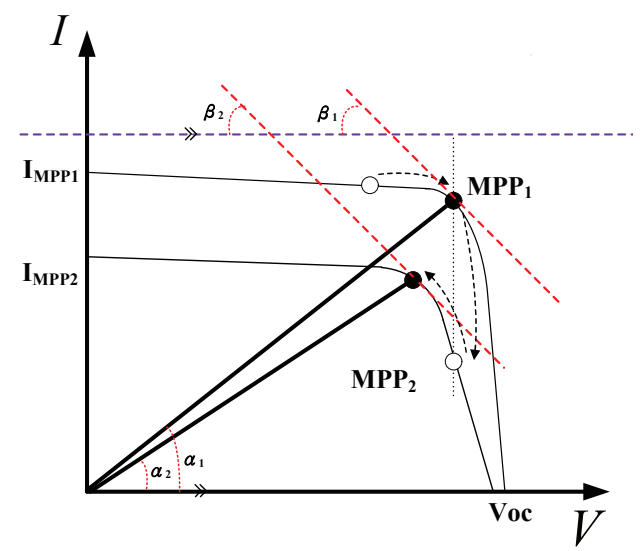

Figure 3. INC tracking process.

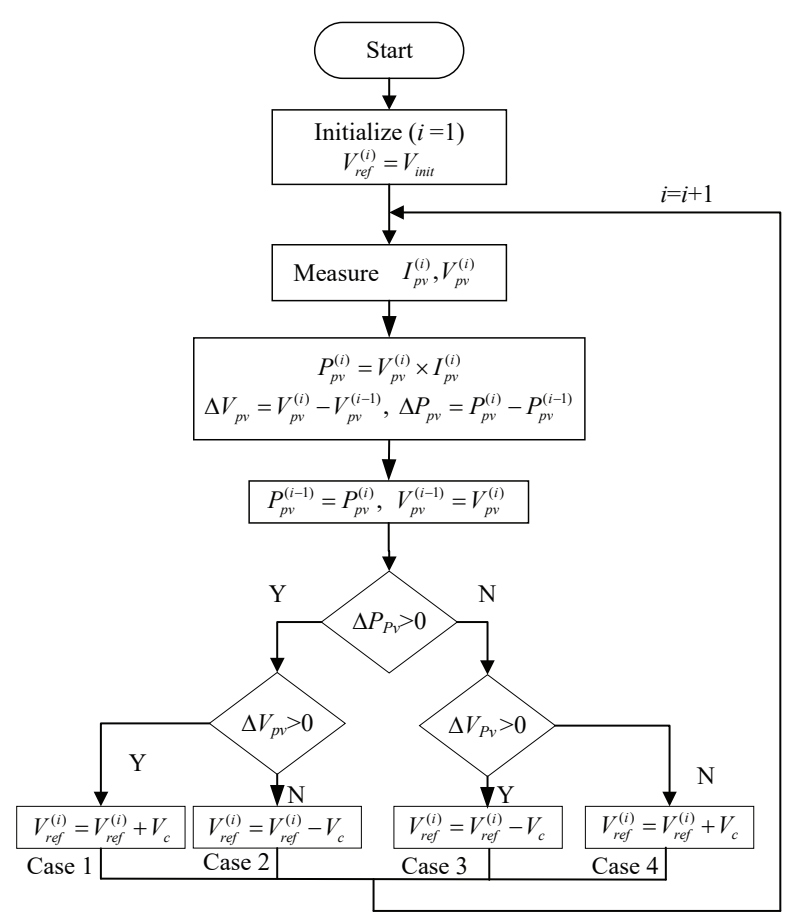

Figure 4. Flowchart of INC method.

\subsection{Golden Section Search}

The GSS method, first proposed by Kiefer in 1953 [31], is classified as an iterative bracketing method without taking any derivatives [32]. This search technique finds an extremum (minimum or maximum) of a function $f(X)$ within a given interval. The basic principle of GSS is to maintain the proportional distance among four points while narrowing the search interval toward the extreme point. As shown in Figure 5, the position of each point should follow the rule that 


$$
\frac{B}{A}=\frac{A-B}{B} .
$$

Solving Equation (4) gives $B / A=1.61803$, known as the golden ratio. Like other bracketing methods, GSS looks for the region in which the maximum point lies. This is achieved by comparing the values of $f\left(X_{1}\right)$ and $f\left(X_{2}\right)$. If $f\left(X_{1}\right)>f\left(X_{2}\right)$, as shown in Figure 5a, then the upper and lower bounds change from $X_{U}$ and $X_{L}$ to $X_{U}$ and $X_{2}$. $X_{1}$ automatically satisfies Equation (4). Hence, we need only find a new internal point, $X_{3}$, which can be obtained by

$$
X_{3}=X_{2}+0.618 \times\left(X_{U}-X_{2}\right) .
$$

If $f\left(X_{2}\right)>f\left(X_{1}\right)$, as shown in Figure $5 \mathbf{b}$, then the upper and lower bounds change from $X_{U}$ and $X_{L}$ to $X_{1}$ and $X_{L}$. $X_{2}$ automatically satisfies (4). Hence, we need only find a new internal point, $X_{3}$, which can be obtained by

$$
X_{3}=X_{1}-0.618 \times\left(X_{1}-X_{L}\right) .
$$

Consequently, the search range shrinks towards the MPP with a constant convergence speed. Kiefer proposed another method based on the Fibonacci series, named the Fibonacci search. Both methods are identical in terms of their principle, but the Fibonacci search uses the ratio of successive terms in the Fibonacci series instead of the golden ratio [33]. A flowchart of the GSS procedure is illustrated in Figure 6. 

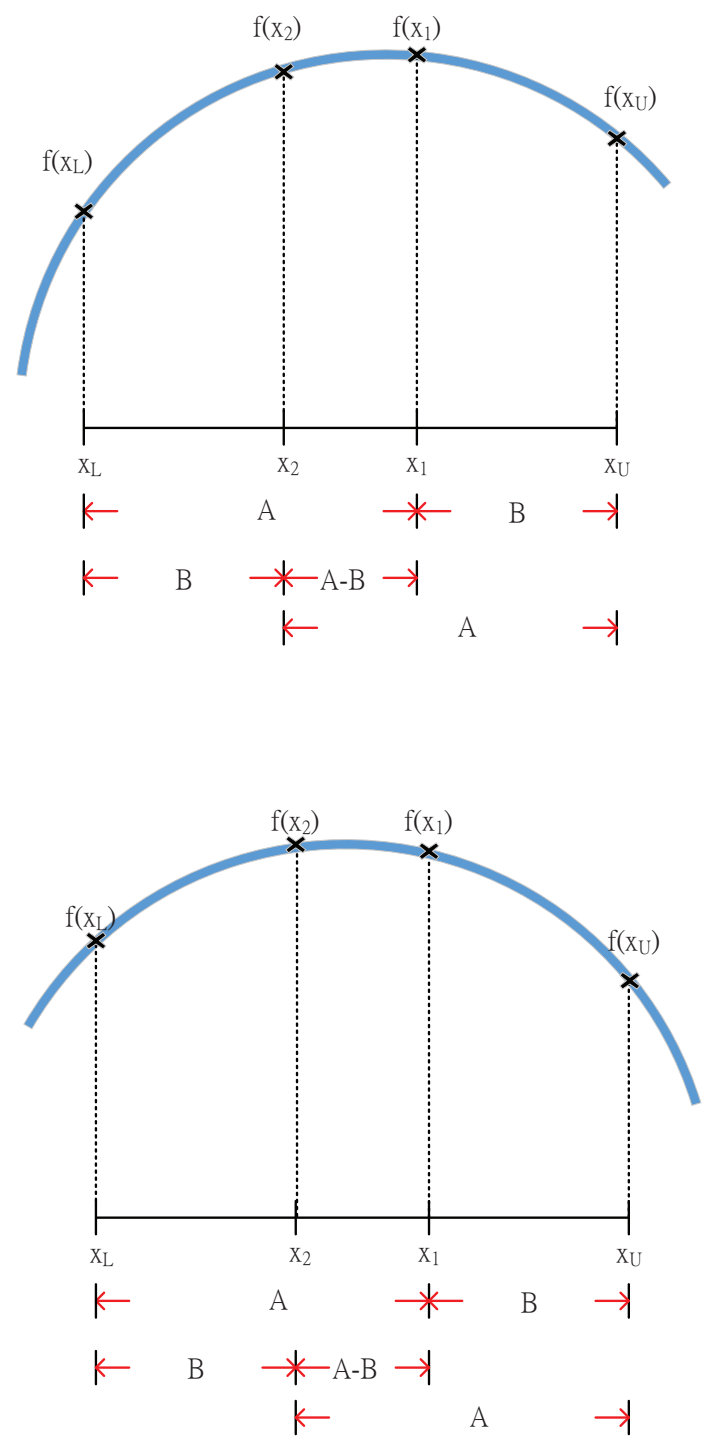

Figure 5. (a) upper: bounded region for $f\left(X_{1}\right)>f\left(X_{2}\right)$; (b) lower: bounded region for $f\left(X_{2}\right)>f\left(X_{1}\right)$. 


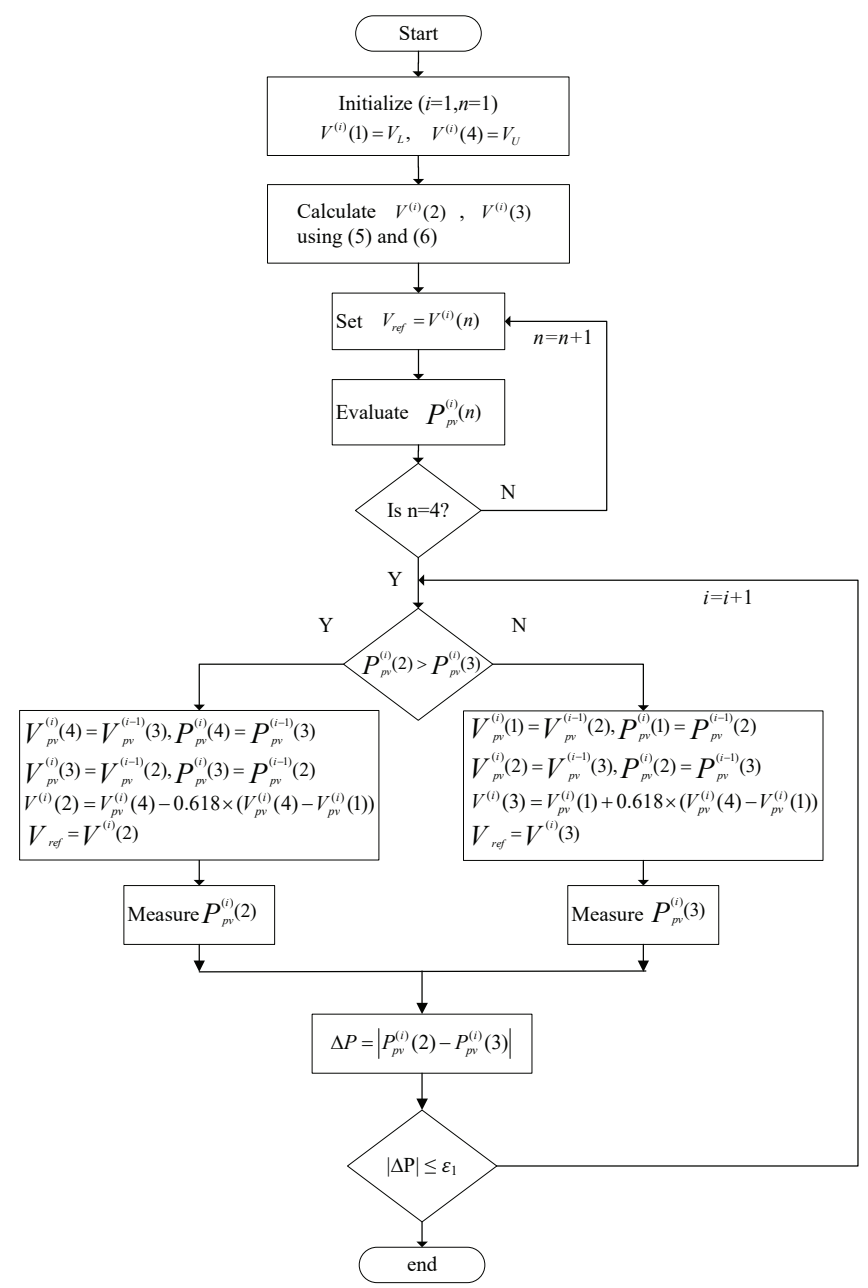

Figure 6. GSS flowchart.

\subsection{Newton Quadratic Interpolation}

As the P-V curve is often parabolic, as shown in Figure 7, a number of researchers have used NQI to estimate the MPP. By first measuring three points on the P-V curve, as shown in Figure 7, the NQI method can be used to approximate a second-order polynomial of the form

$$
f(V)=B_{1}+B_{2}\left(V-V_{1}\right)+B_{3}\left(V-V_{1}\right)\left(V-V_{2}\right),
$$

where $B_{1}=P_{1}, B_{2}=\frac{P_{2}-P_{1}}{V_{2}-V_{1}}$, and $B_{3}=\frac{P_{3}-P_{2}-P_{2}-P_{1}}{V_{2}-V_{2}-V_{1}}$.

The maximum point can be obtained by setting the first derivative of Equation (7) to be zero. Thus, the MPP can be estimated as

$$
V_{m p p}=\frac{1}{2}\left(\left(V_{1}+V_{2}\right)-\frac{B_{2}}{B_{3}}\right) .
$$

Figure 7 illustrates the NQI procedure for reaching the MPP. Figure 7a shows the estimated MPP (white circle) for the given three initial measurements. As the process continues, the estimated MPP becomes closer to true MPP, as shown in Figure $7 \mathrm{~b}$. The process is repeated until the convergence condition is reached.

Figure 8 shows a flowchart of the NQI process. Essentially, the MPP is estimated by Equation (8) via three points. The point with the lowest power is then dropped, a new point is selected, and the remaining three points are used to predict the maximum point. The procedure is repeated until the 
convergence condition is reached. Instead of dropping the worst power point, some scholars [21] drop the leftmost and rightmost points alternately. The subsequent discussion is based on the approach shown in Figure 8, as similar statements can be applied to the alternative approach.
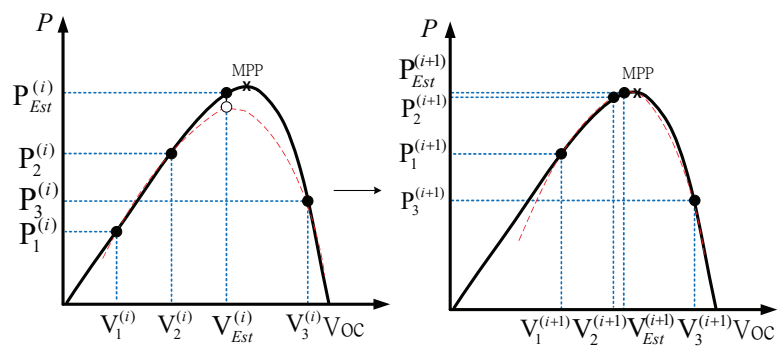

Figure 7. NQI tracking process.

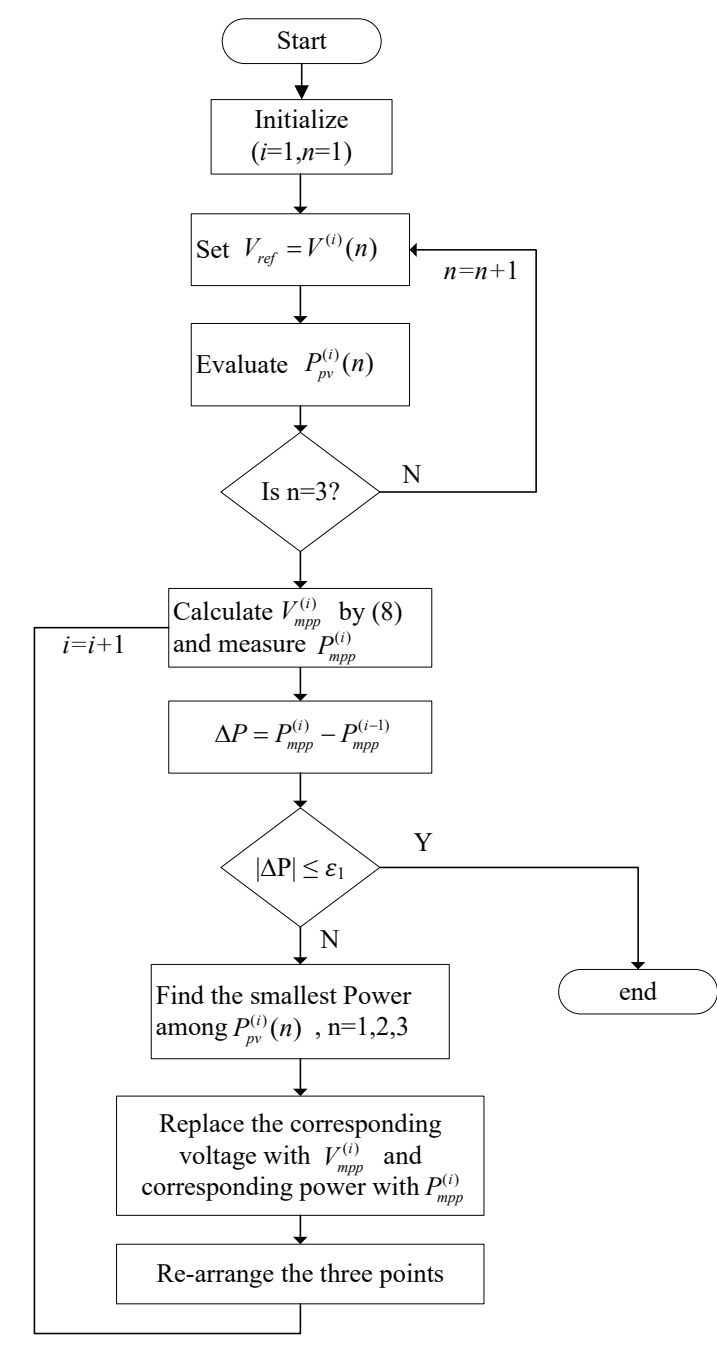

Figure 8. NQI flowchart.

\section{Discussion}

This section provides a general discussion on the four algorithms described in Section 2. We consider the initialization and convergence criteria through simulation tests conducted using a Matlab platform (2016a, MathWorks, Massachusetts, USA), which is similar to that of [34]. The I-V curves are obtained from an extensive database of measured module parameters. Note that, in this 
paper, our focus is on the perspective of numerical analysis of the four algorithms. Hence, we will thoroughly discuss only the initialization setting and convergence criteria. Nevertheless, there are other factors such as the levels of granularity for DMPPT and the measurement errors may also affect the DMPPT algorithms. However, the discussion of these factors are beyond the scope of this paper. As mentioned in Section 1, we assume that at substring level, the P-V curve exhibits a single peak so that we only focus on the performance of the algorithms for the single-peak problem. Moreover, we have also assumed that the measurements are not contaminated with noise and they do not interfere the DMPPT algorithms.

\subsection{Simulation Platform}

A Matlab platform was built to test the four DMPPT algorithms for the micro-converter setup, which is redrawn in Figure 9a. Without loss of generality and for algorithm comparison, we focus on a single DMPPT controller, as shown by the dashed circle in Figure 9a. Figure 9b shows the equivalent system under study and Figure 10 shows the overall block diagram of the proposed Matlab testing platform. As shown in Figure 10, either static or dynamic testing can be selected through the mode selection block. The irradiance, temperature, and PV-type are then imported from a database corresponding to the selected test mode. Figure 11 shows the equivalent circuit model of the PV cell. In this paper, the model is provided in the form of an equation. The assigned parameters will determine the form of the $\mathrm{P}-\mathrm{V}$ and $\mathrm{I}-\mathrm{V}$ curves. Figure 12 shows the $\mathrm{I}-\mathrm{V}$ and $\mathrm{P}-\mathrm{V}$ characteristics under various irradiation conditions, whereas Figure 13 shows the $\mathrm{I}-\mathrm{V}$ and $\mathrm{P}-\mathrm{V}$ characteristics under various temperatures. We can clearly see that $V_{m p p}$ and $V_{o c}$ deviate more significantly under temperature changes than under irradiance changes. Eleven cells are connected in series to build one PV module. Under $1000 \mathrm{~W} / \mathrm{m}^{2}$, each cell has the parameter values listed in Table 1. In the MPPT algorithm block, we can select the algorithm and set the related parameters. Finally, the PV model and algorithm are integrated with the power conversion block to obtain the tracking profile.

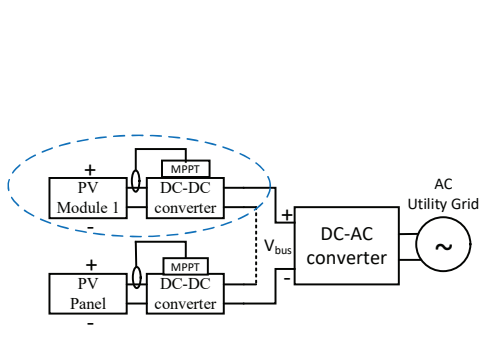

(a)

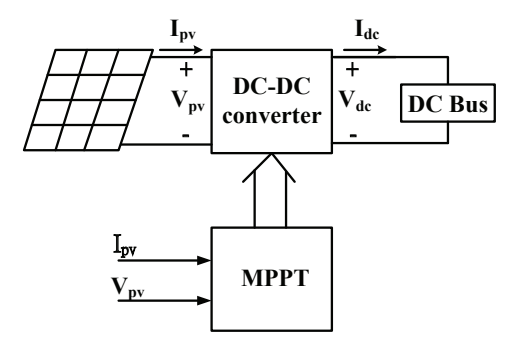

(b)

Figure 9. PV system setup (a) DMPPT topology, (b) Enlarged version of a single DMPPT system.

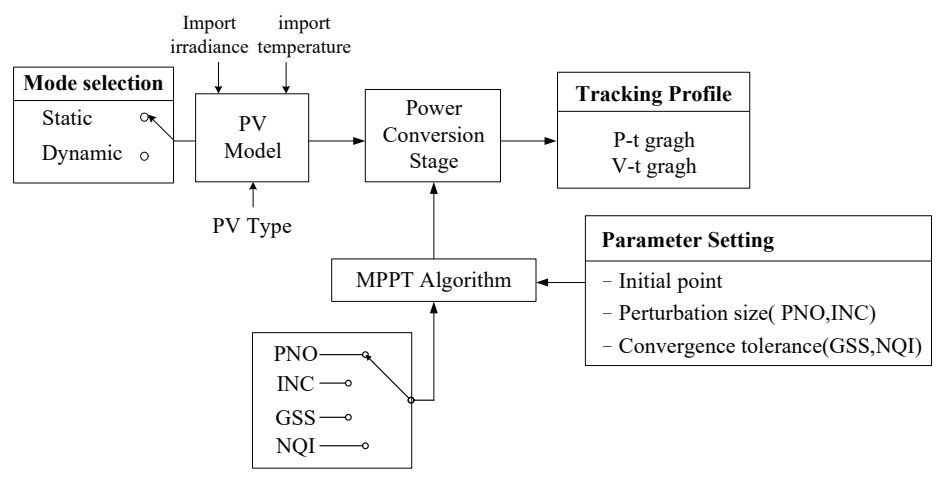

Figure 10. Matlab testing platform. 


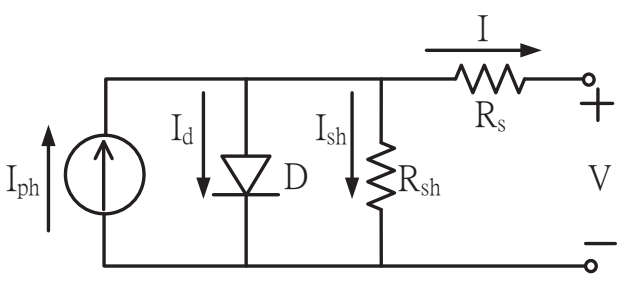

Figure 11. PV-equivalent circuit.

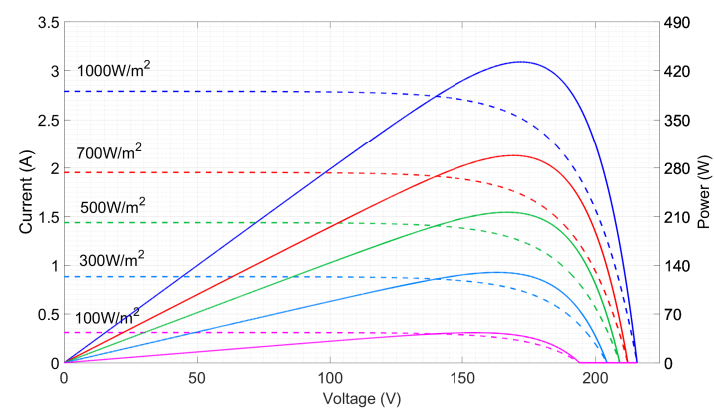

Figure 12. Variation of irradition.

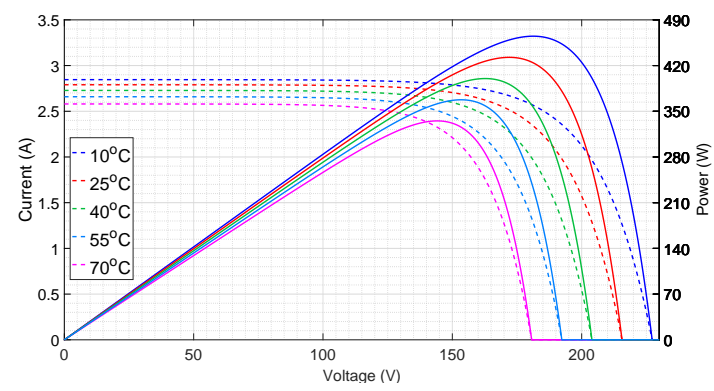

Figure 13. Variation of temperature.

Table 1. PV cell parameters.

\begin{tabular}{cc}
\hline Parameters & Value \\
\hline Maximum Power $\left(P_{\max }\right)$ & $39.318 \mathrm{~W}$ \\
Open Circuit Voltage $\left(V_{o c}\right)$ & $19.6 \mathrm{~V}$ \\
Maximum Power Voltage $\left(V_{m p}\right)$ & $15.634 \mathrm{~V}$ \\
Short Circuit Current $\left(I_{s c}\right)$ & $2.79 \mathrm{~A}$ \\
Maximum Power Current $\left(I_{m p}\right)$ & $2.5149 \mathrm{~A}$ \\
Temperature Coefficient $\left(\beta_{v}\right)$ & $-0.36 \% / \mathrm{K}$ \\
\hline
\end{tabular}

\subsection{Initialization}

The goal of this section is to investigate whether the initial points (IPs) affect the tracking time or accuracy. As $P \& O$ and INC only involve a single particle, the tracking time will increase with the distance of the particle from the MPP. However, the IP locations for both P\&O and INC do not affect the final accuracy. Nevertheless, the perturbation size can affect the accuracy. Figure 14a,b show the performance of $P \& O$ and INC, respectively. The results show that there is an inevitable trade-off between the accuracy and the tracking time of the $P \& O$ and INC algorithm. The perturbation size is inversely proportional to both the accuracy and the tracking time. 


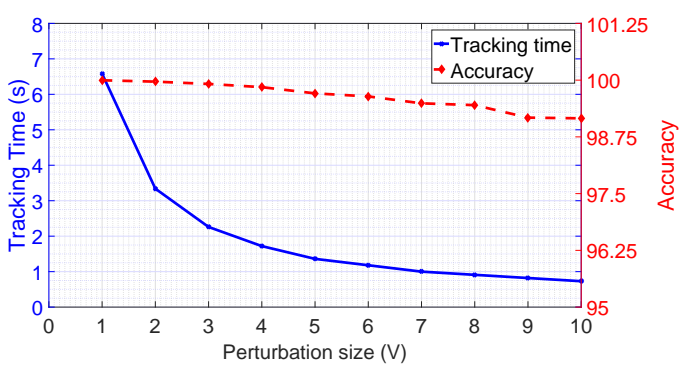

(a)

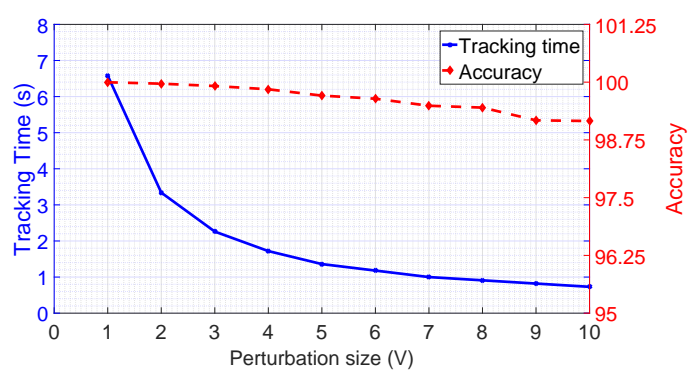

(b)

Figure 14. Efficiency and tracking time of various methods under various parameter calibrations.

(a) $P \& O$; (b) INC.

In the case of GSS, the only condition required to ensure that the MPP is reached is that the IPs must bracket the MPP. Figure 15 shows an example in which the initial points of GSS do not bracket the MPP. In this condition, GSS fails to track the MPP. The algorithm converges to the upper bound of the search area. Figure 16 shows that if the MPP is bracketed by the IPs, MPPT can be achieved.

Unlike the previous three algorithms, which directly search for the MPP, NQI employs polynomial interpolation to estimate the MPP. Thus, the setting of the initial conditions could greatly affect its accuracy and convergence speed. By thoroughly investigating different initial conditions, we find that, if one of the following four cases occurs, NQI will fail to track the MPP. For example, Figure 17a shows that when the IPs $\left(V_{2}, P_{2}\right)$ and $\left(V_{3}, P_{3}\right)$ are placed at the same power level $\left(P_{2}=P_{3}\right)$ and the other point $\left(V_{1}, P_{1}\right)$ is placed as indicated, the first estimated MPP is predicted by the first parabola, which is formed by the three IPs. As $P_{1}$ has the lowest power, it is discarded. Therefore, in the second iteration, the three IPs are $\left(V_{1}^{\prime}, P_{1}^{\prime}\right),\left(V_{2}^{\prime}, P_{2}^{\prime}\right)$, and $\left(V_{3}^{\prime}, P_{3}^{\prime}\right)$, which form the second parabola. Note that $V_{1}^{\prime}=V_{2}, P_{1}^{\prime}=P_{2}, V_{2}^{\prime}=V_{m e}, P_{2}^{\prime}=P_{m e}, V_{3}^{\prime}=V_{3}, P_{3}^{\prime}=P_{3}$. The next estimated MPP $\left(V_{m e}^{\prime}, P_{m e}^{\prime}\right)$ is then coincident with $\left(V_{m e}, P_{m e}\right)$. Therefore, the iteration will terminate. Similar situations can be observed in Figure 17b-d. We refer to this situation as the "NQI trap" because once it occurs during the iteration process, the NQI cannot proceed to track the MPP. This is something that has never been reported in the literature.

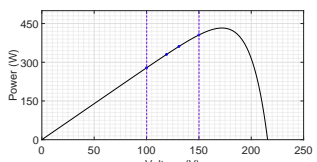

(a)

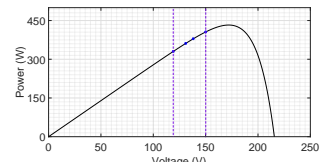

(b)

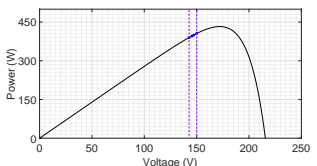

(e)

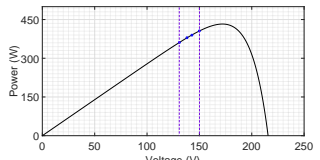

(c)

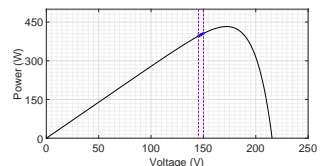

(f)

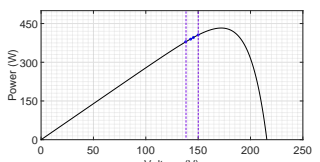

(d)

Figure 15. GSS not bracketing MPP. (a) 1st; (b) 2nd; (c) 3rd; (d) 4th; (e) 5th; and (f) 6th iteration. 


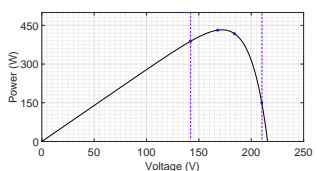

(a)

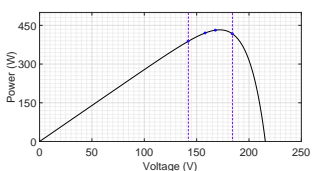

(b)

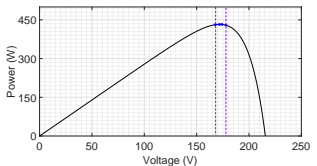

(e)

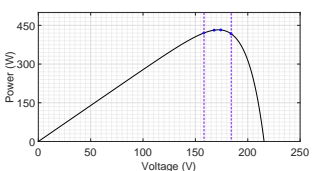

(c)

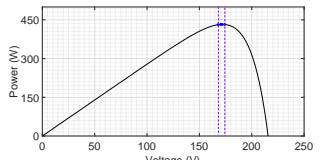

(f)

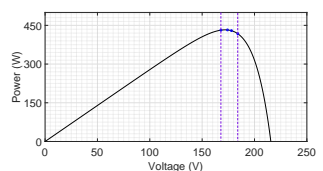

(d)

Figure 16. GSS bracketing MPP. (a) 1st; (b) 2nd; (c) 3rd; (d) 4th; (e) 5th; and (f) 6th iteration.

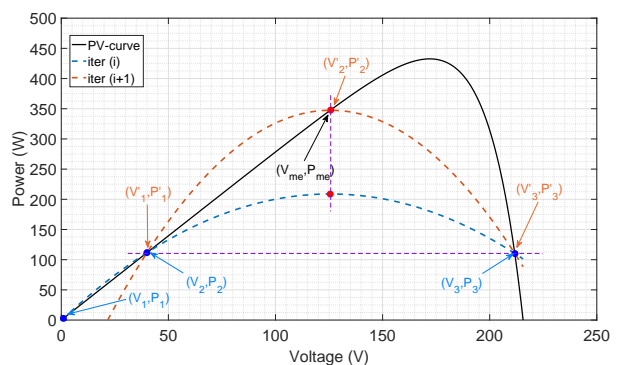

(a)

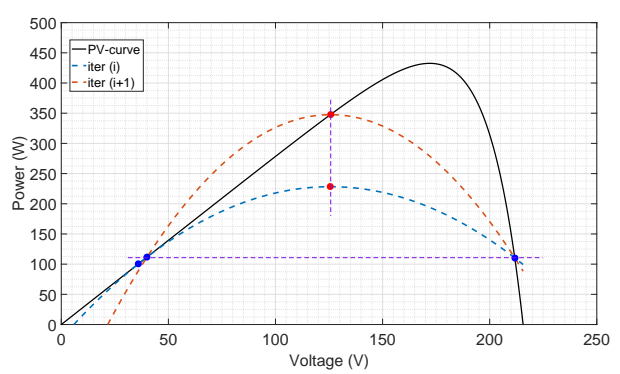

(c)

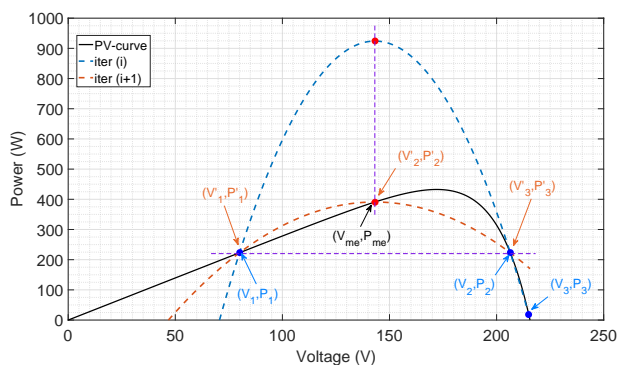

(b)

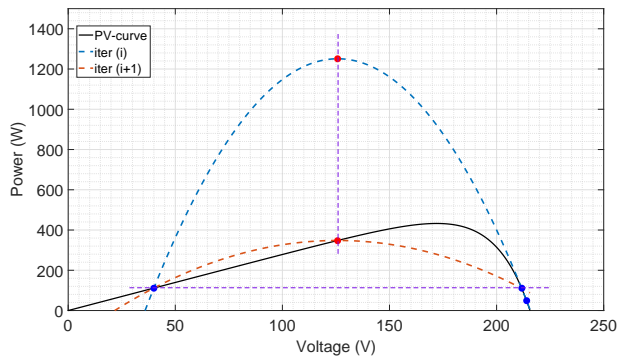

(d)

Figure 17. The "NQI trap" occurs when two IPs have the same power level and the third has the lowest power. $(\mathbf{a}, \mathbf{b})$ lowest power IP is below the left point; $(\mathbf{c}, \mathbf{d})$ lowest power IP is below the right point.

As long as the NQI trap can be avoided, NQI can track the MPP. Figure 18 shows how the NQI can still track the MPP when the three IPs are set very close to each other or placed at the far right-/left-hand-side of the PV curve.

\subsection{Convergence Criteria}

As observed in Figures 2 and 4, $P \& O$ and INC do not require convergence criteria, and simply repeat the update process continuously. Moreover, these two methods do not require any re-start mechanisms when the $\mathrm{P}-\mathrm{V}$ curve changes because of variations in irradiance or temperature. However, $P \& O$ and INC suffer from the problem of oscillation. Note that, contradictory to its general conception, INC still suffers from the oscillation problem, as pointed out in $[35,36]$. Convergence criteria can be applied to $P \& O$ and INC to mitigate the steady-state fluctuations. However, the tolerance value must be set carefully. If the tolerance is too small, oscillations may still occur. $\Delta P_{p v}$ can be used to detect sudden changes in the PV curve. However, the detected power value should not be confused with the convergence condition. For example, consider the settings of $\Delta P_{p v}<\epsilon_{1}$ for convergence to the MPP and $\Delta P_{p v}>\epsilon_{2}$ for detecting power changes. $\epsilon_{1}$ should be much smaller than $\epsilon_{2}$. If the tolerance coincides 
with the power perturbation, then the solution will converge prematurely. Femia et al. [37] showed how a theoretical optimized value can be obtained. Figure 19 shows a state diagram representing the dynamic tracking process for algorithms with convergence criteria.

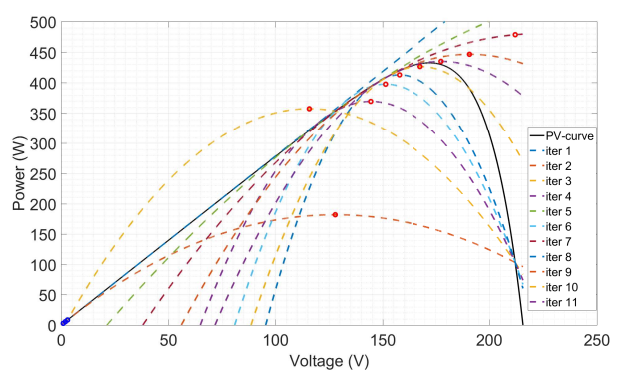

(a)

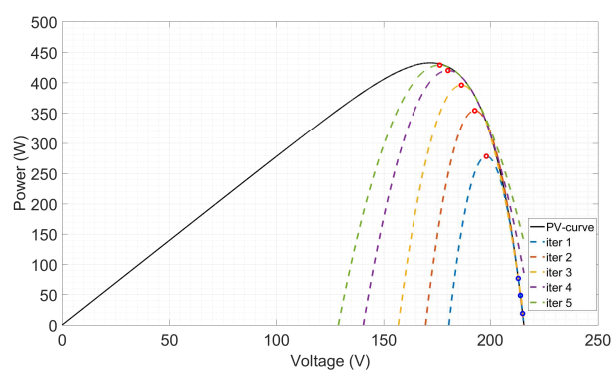

(b)

Figure 18. NQI tracking process under 100\% irradiation with initial points (a) $1 \mathrm{~V}, 2 \mathrm{~V}, 3 \mathrm{~V}$; (b) $213 \mathrm{~V}$, $214 \mathrm{~V}, 215 \mathrm{~V}$.

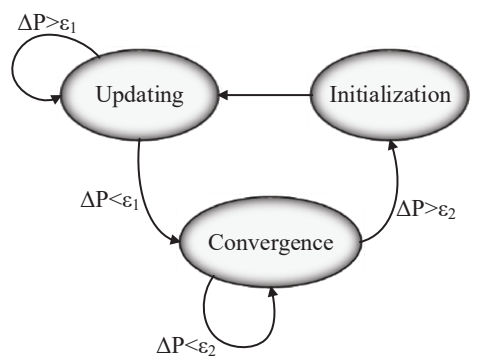

Figure 19. State diagram for dynamic tracking process with GSS and NQI.

As shown in Figures 6 and 8, GSS and NQI generally require convergence criteria; otherwise, numerical errors may occur. Figure 20 shows the overfitting problem faced by NQI when no convergence criteria are imposed. As the figure indicates, the concave-down parabola eventually becomes a concave-up parabola. For GSS, the golden ratio may be violated when no convergence condition is imposed because the search area will shrink down to a single point.

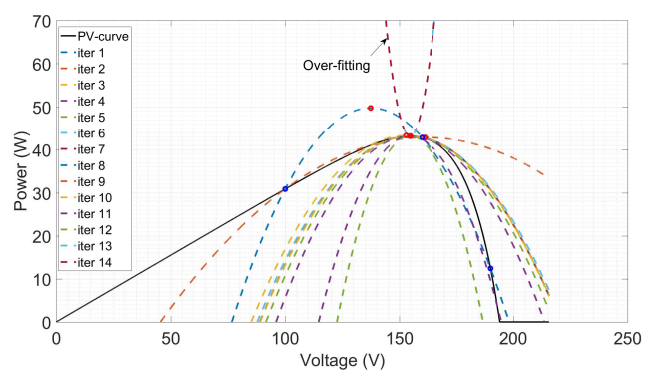

Figure 20. Overfitting case of NQI.

The convergence criteria selected for GSS and NQI need to be set carefully, as some conditions may lead to serious problems when the irradiance changes rapidly. For GSS, if the convergence criterion is set to

$$
\Delta V_{p v}=V_{U}-V_{L}<\varepsilon_{1}
$$

the solution may converge, but the converged point may not be the true MPP. This can be seen from Figure 21. Initially, the four IPs are as indicated in Figure 21a. As $P_{3}^{(1)}>P_{2}^{(1)}$, the search area is as indicated in the figure. If the irradiance suddenly changes, the PV curve changes to that shown in 
Figure 21b, and the four IPs are those shown in the figure, where $\left(V_{1}^{(2)}, P_{1}^{(2)}\right)$ and $\left(V_{4}^{(2)}, P_{4}^{(2)}\right)$ are the lower and upper bounds, respectively. Note that $\left(V_{1}^{(2)}, P_{1}^{(2)}\right)$ and $\left(V_{2}^{(2)}, P_{2}^{(2)}\right)$ are indicated by hollow circles because, even though those points do not physically exist, their values are kept in the memory. Consequently, the search area is now between $\left(V_{1}^{(2)}, P_{1}^{(2)}\right)$ and $\left(V_{3}^{(2)}, P_{3}^{(2)}\right)$, as indicated in the figure. Note that this search area does not bracket the MPP. Continuing with the process, the four IPs are as indicated in Figure 21c, with the corresponding search area also shown. Note that $\left(V_{1}^{(3)}, P_{1}^{(3)}\right)$ and $\left(V_{3}^{(3)}, P_{3}^{(3)}\right)$ are indicated by hollow circles because their values are taken from the previous iteration. On the fourth iteration, $\left(V_{1}^{(3)}, P_{1}^{(3)}\right)$ are physically replaced by other values, as indicated in Figure $21 \mathrm{~d}$, and the corresponding search area is further away from the MPP. Finally, in the next iteration, the search area moves much further away from the MPP, as indicated in Figure 21e. Therefore, the solution converges to a point away from the MPP. Figure 22 shows the tracking profile of GSS when the irradiance changes suddenly, where GSS clearly fails to track the MPP. This problem cannot be resolved using different convergence criteria. When $\Delta P=\left|P_{2}-P_{3}\right|<\epsilon$ is used as the convergence criterion, the scheme will never converge because there is always a large gap between $P_{2}$ and $P_{3}$, as shown in Figure 21 .

NQI suffers from a similar problem, as illustrated in Figure 23. In Figure $23, V_{1}^{(1)}, V_{2}^{(1)}$, and $V_{3}^{(1)}$ are taken as the IPs, and the first prediction $\left(V_{m e}^{(1)}, P_{m e}^{(1)}\right)$ is obtained by $(8)$. By eliminating $\left(V_{1}^{(1)}, P_{1}^{(1)}\right)$ and sorting the remaining three points in ascending order, $\left(V_{m e}^{(2)}, P_{m e}^{(2)}\right)$ is obtained. However, if the irradiance suddenly changes, the nature of NQI to eliminate the smallest power at every iteration means that $\left(V_{1}^{(2)}, P_{1}^{(2)}\right)$ and $\left(V_{2}^{(2)}, P_{2}^{(2)}\right)$ will never be re-evaluated although the power corresponding to those voltages has changed. Consequently, future predictions will move in the wrong direction. We can clearly observe from Figure 23d,e that the tracking process will not only converge to a point which is far away from the MPP, but also generate an incorrect prediction curve as a concave-up parabola. Figure 24 shows the tracking profile of NQI, which clearly fails to track the MPP.

$\mathrm{P} \& \mathrm{O}$ and INC are more rigorous when faced with sudden PV curve changes. This is evident from Figures 25 and 26, where both algorithms successfully track the MPP under sudden changes in irradiance.

\subsection{Final Remark}

In general, if the initial conditions and convergence criteria are well selected, all four algorithms can perform equally well. Figures 27 and 28 shows the tracking profile when the irradiance changes from $30 \%$ to $100 \%$ and back to $30 \%$ with a dwell time of $10 \mathrm{~s}$ and slope of $30 \mathrm{~W} / \mathrm{m}^{2} / \mathrm{s}$ (EN50530:2010 Table B.2 [38], row 4). It is clear that all algorithms can track the MPP if the irradiance does not change very rapidly. Nevertheless, NQI and GSS exhibit relatively large transients, whereas those of $P \& O$ and INC are relatively small. The tracking efficiency for the dynamic cases $\left(\eta_{d}\right)$ is calculated based on the following formula:

$$
\eta_{d}=\frac{\sum_{i} V_{p v, i} \cdot I_{p v, i} \cdot \Delta T_{i}}{\sum_{j} G M P_{t h, j} \cdot \Delta T_{j}} \times 100 \%,
$$

where $\Delta T_{j}$ is the period in which the $G M P_{t h, j}$ is provided and $\Delta T_{i}$ is the period in which the $V_{p v, i}$ and $I_{p v, i}$ are sampled.

The dynamic efficiency of P\&O, INC, GSS, and NQI are respectively 99.90\%, 99.91\%, 99.51\%, and $99.62 \%$. To validate these simulation results, an experimental test is conducted. The PV array in the experimental setup is realized by a programmable PV emulator manufactured by AMETEK (Model ETS600X8C-PVF) (San Diego, CA, USA). The PV emulator is able to exhibit the PV profile under irradiance changes as well as temperature changes. The DC-DC converter, connected to the PV emulator is a boost converter. A 32-bit digital signal processor (DSP-TMS320F28035) is implemented as a DMPPT controller. The complete setup parameter can be found in [40]. Figure 29 shows the experimental dynamic tests of P\&O, INC, GSS, and NQI. The dynamic efficiency of P\&O, INC, GSS, 
and NQI from the experiment are respectively $99.89 \%, 99.87 \%, 99.28 \%$, and $99.44 \%$. As we can see, the simulation result shows that INC outperform $\mathrm{P} \& \mathrm{O}$ by $0.01 \%$, but the experimental result shows that $\mathrm{P} \& \mathrm{O}$ outperform INC by $0.02 \%$. With this insignificant difference, we can conclude that $\mathrm{P} \& \mathrm{O}$ and INC have equally good performance. The dynamic efficiencies of GSS and NQI from the experiment follow similar trends as those of the simulation. That is, NQI generally outperforms GSS. Generally speaking, if the parameters related to the algorithm are well selected, the four algorithms can achieve efficiency of almost $100 \%$.

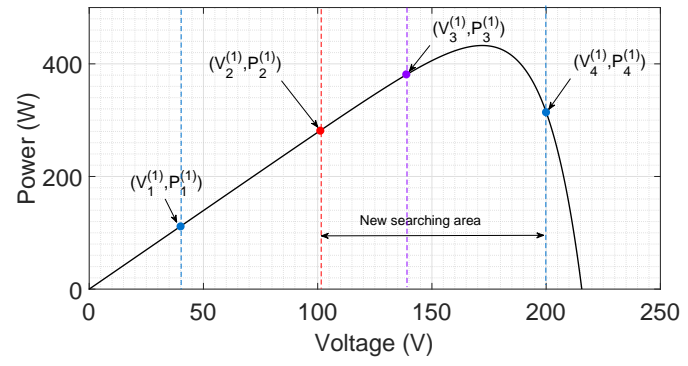

(a)

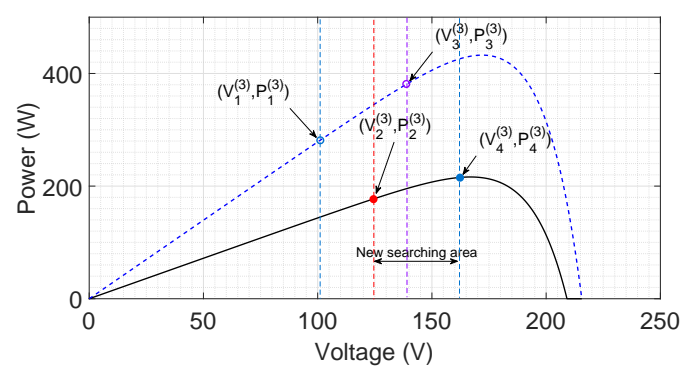

(c)

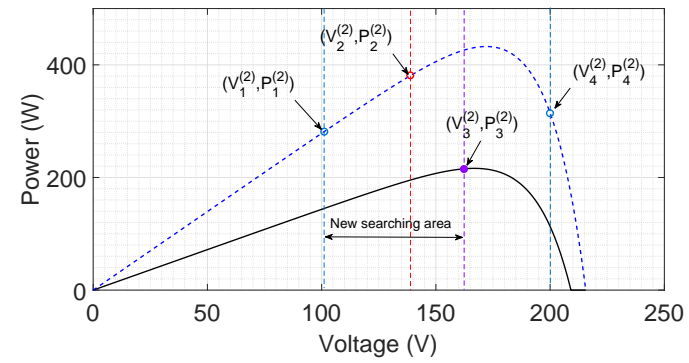

(b)

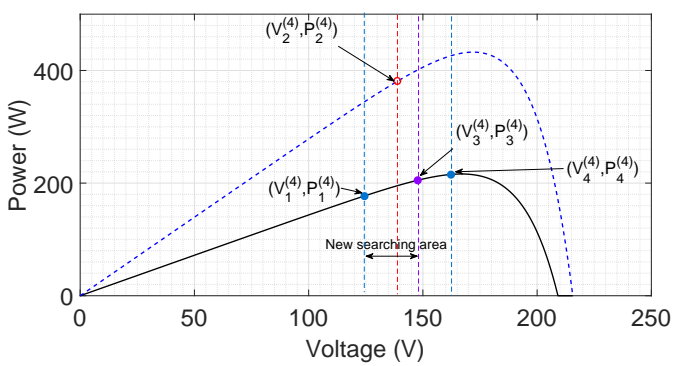

(d)

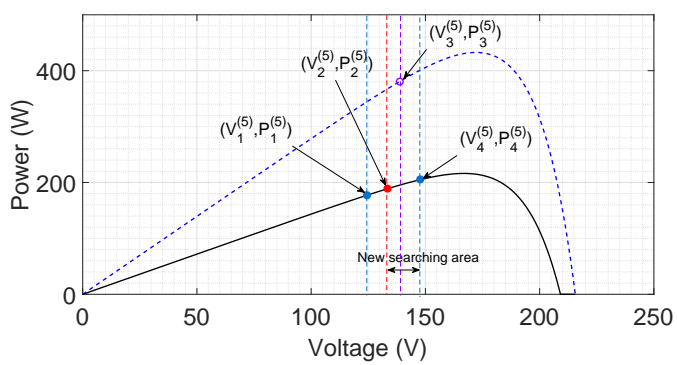

(e)

Figure 21. GSS under sudden irradiance changes. (a) 1st; (b) 2nd; (c) 3rd; (d) 4th; and (e) 5th iteration.
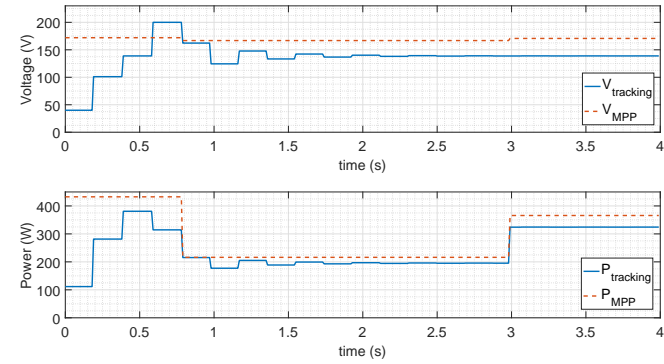

Figure 22. Tracking profile of GSS under sudden irradiance changes. 


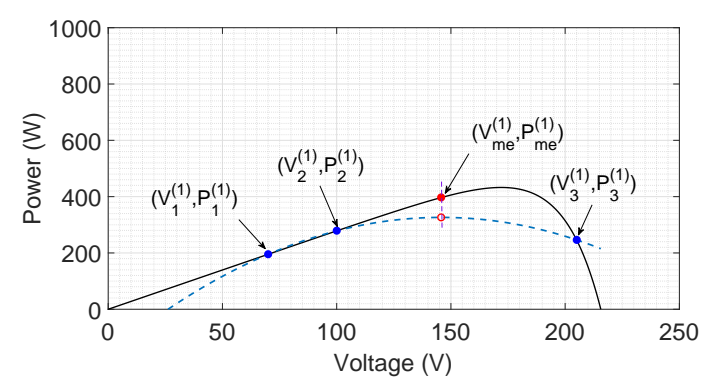

(a)

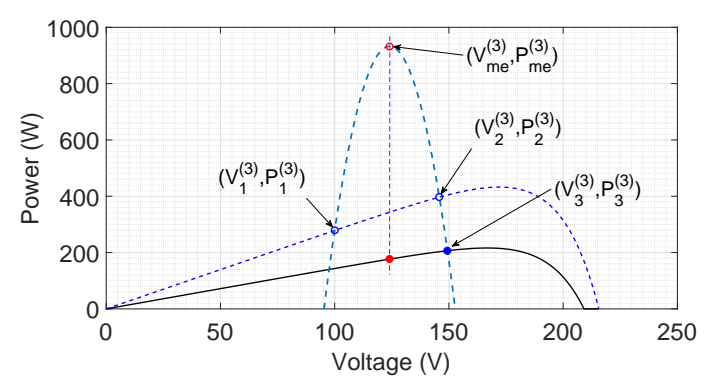

(c)

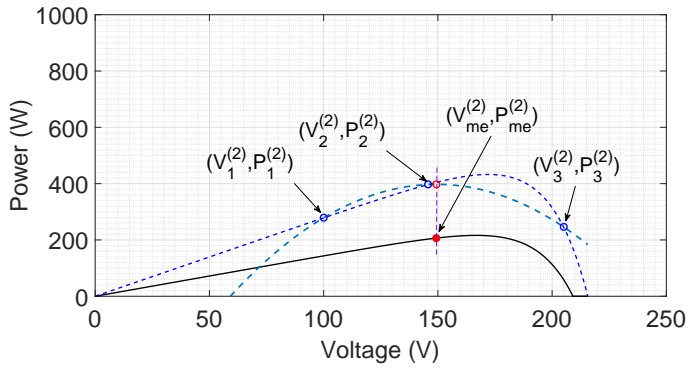

(b)

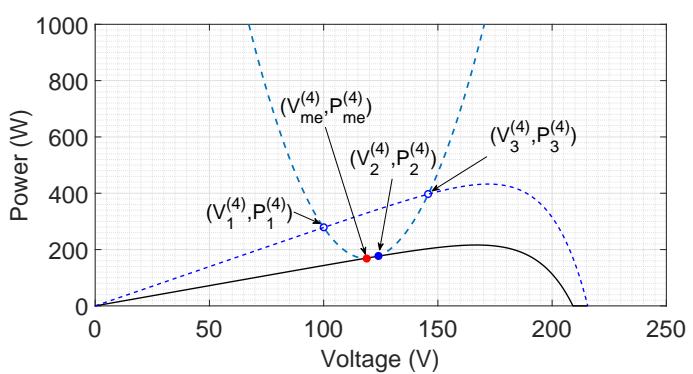

(d)

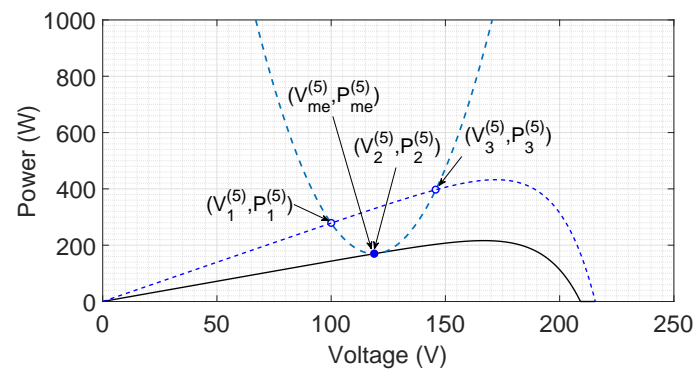

(e)

Figure 23. NQI under sudden irradiance changes. (a) 1st; (b) 2nd; (c) 3rd; (d) 4th; and (e) 5th iteration.
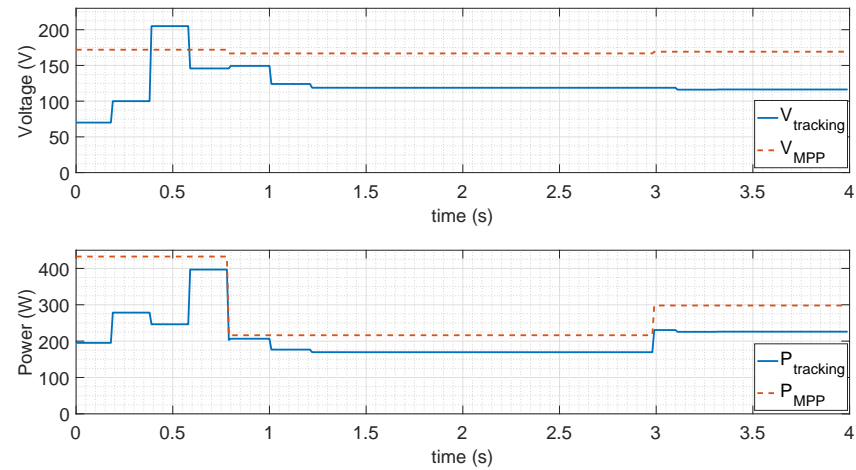

Figure 24. Tracking profile of NQI under sudden irradiance changes. 

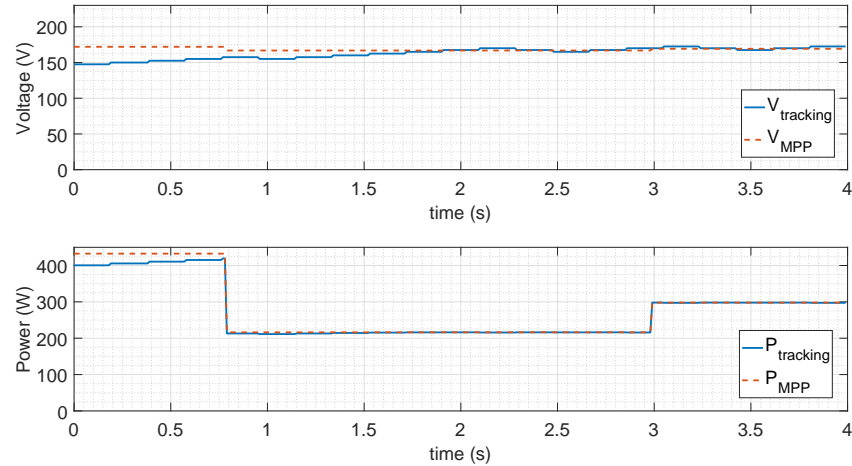

Figure 25. Tracking profile of $P \& O$ under sudden irradiance changes.
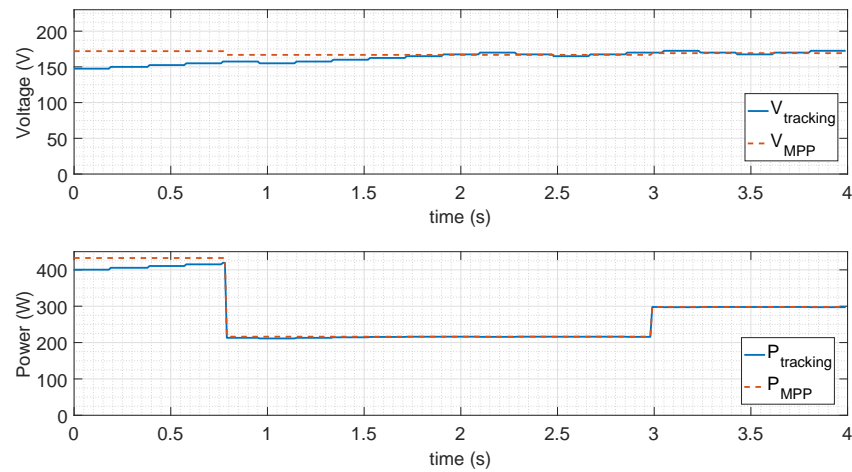

Figure 26. Tracking profile of INC under sudden irradiance changes.
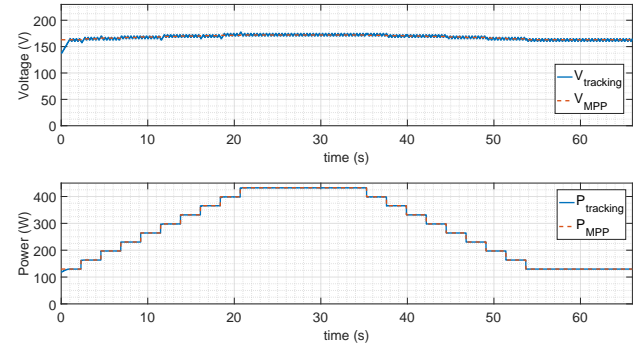

(a)
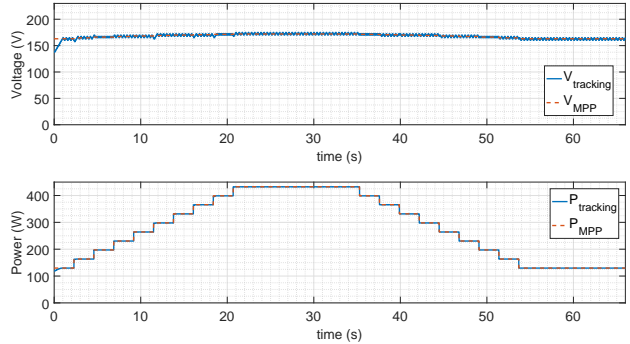

(b)

Figure 27. Dynamic test based on EN 50530:2010. (a) $P \& O$; (b) INC.
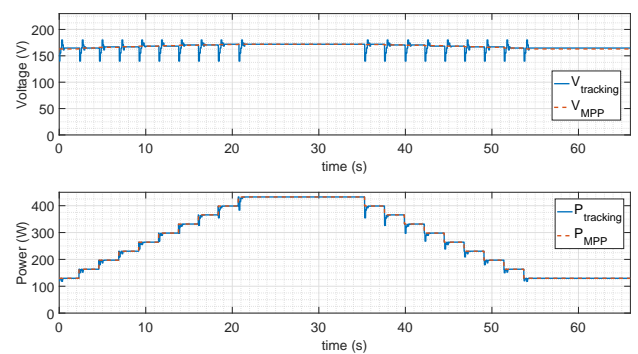

(a)
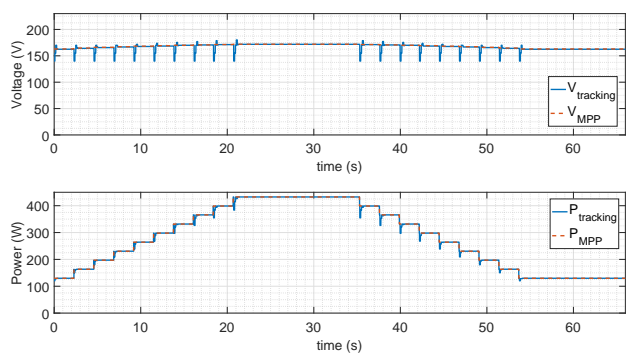

(b)

Figure 28. Dynamic test based on EN 50530:2010. (a) GSS; (b) NQI. 

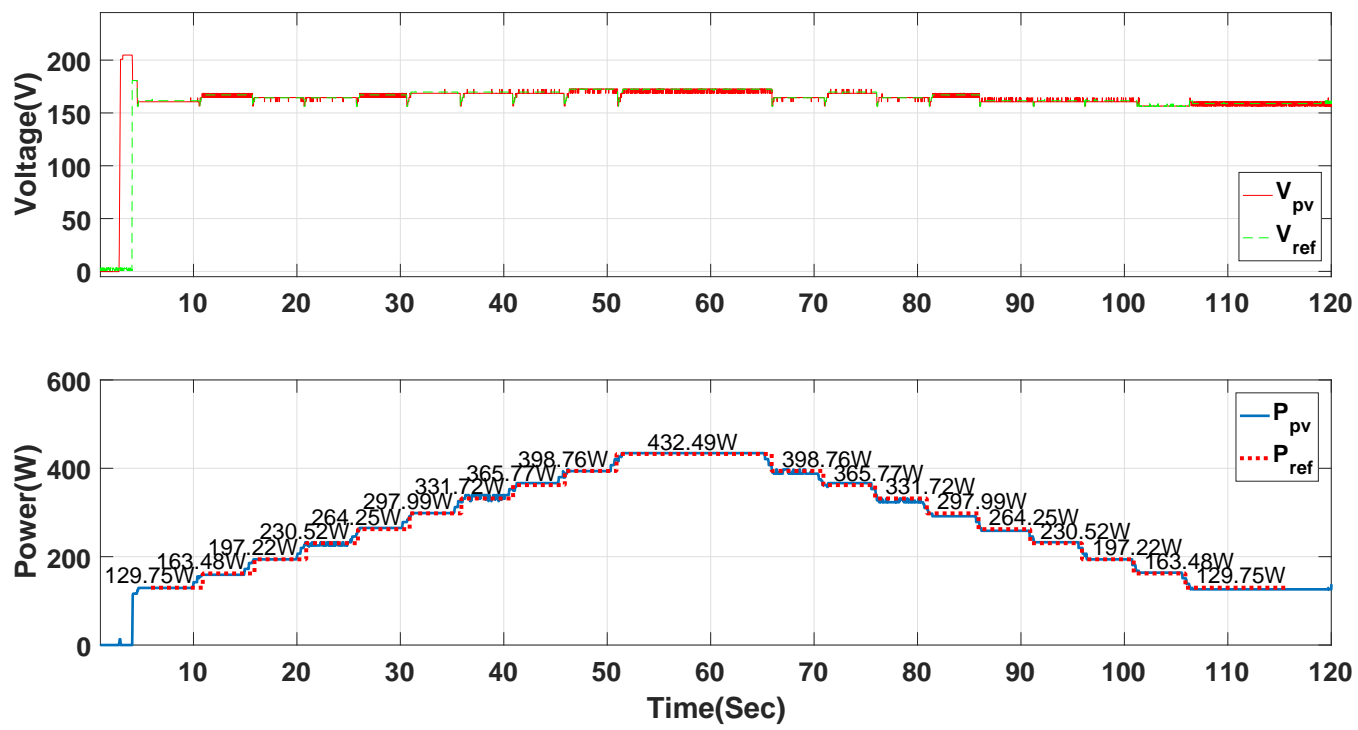

(a)
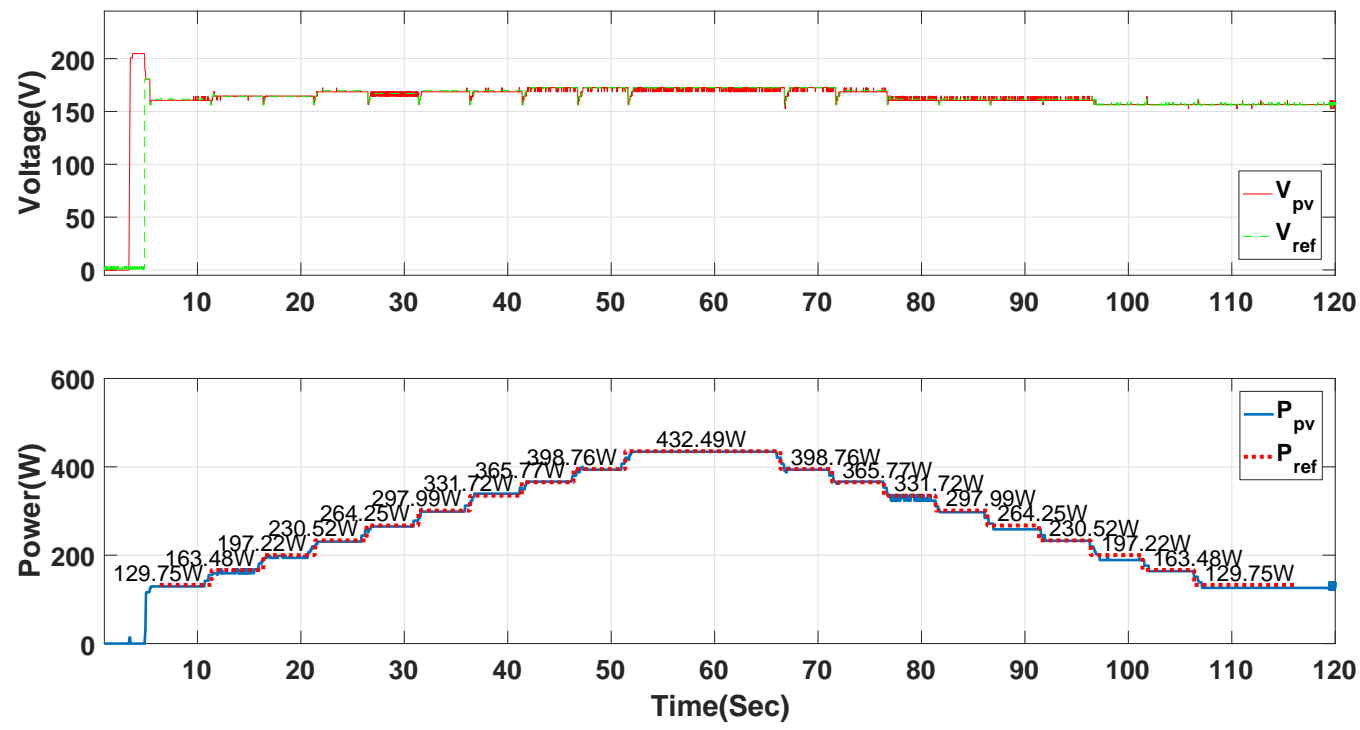

(b)
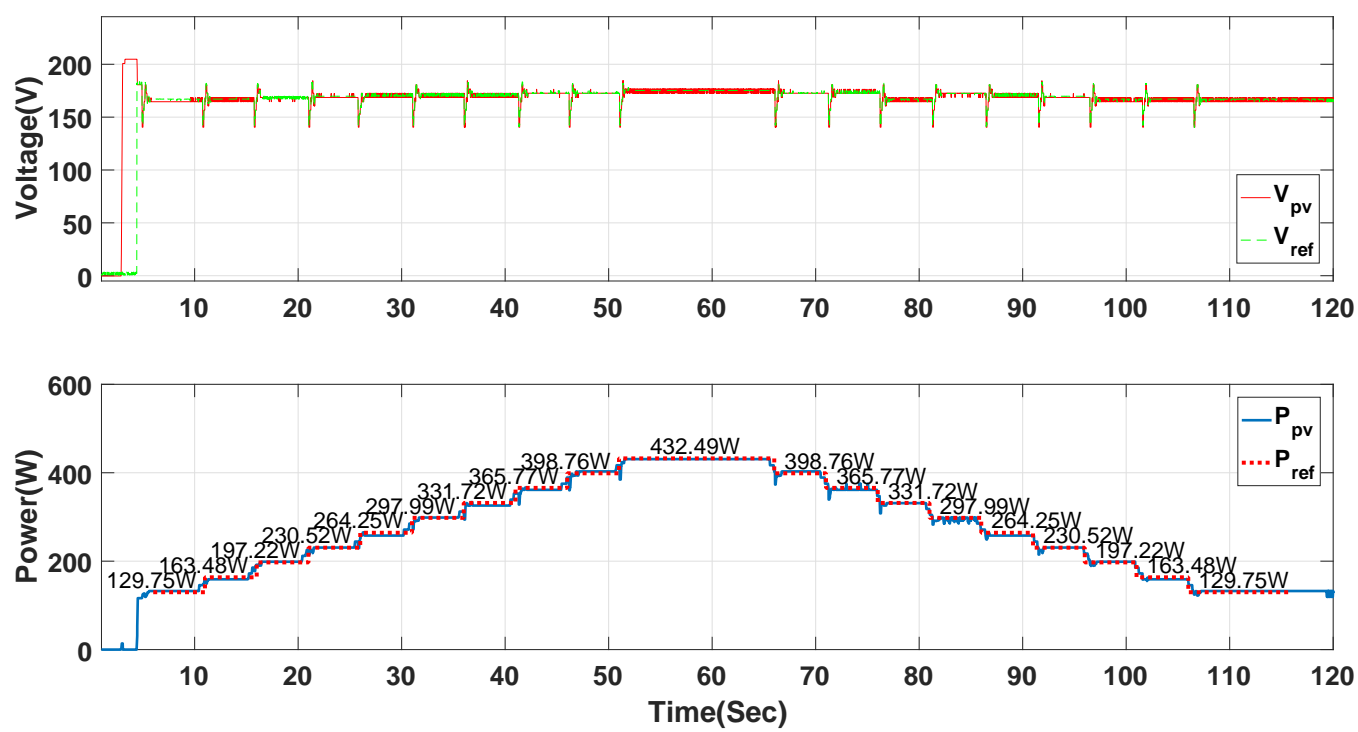

(c)

Figure 29. Cont. 

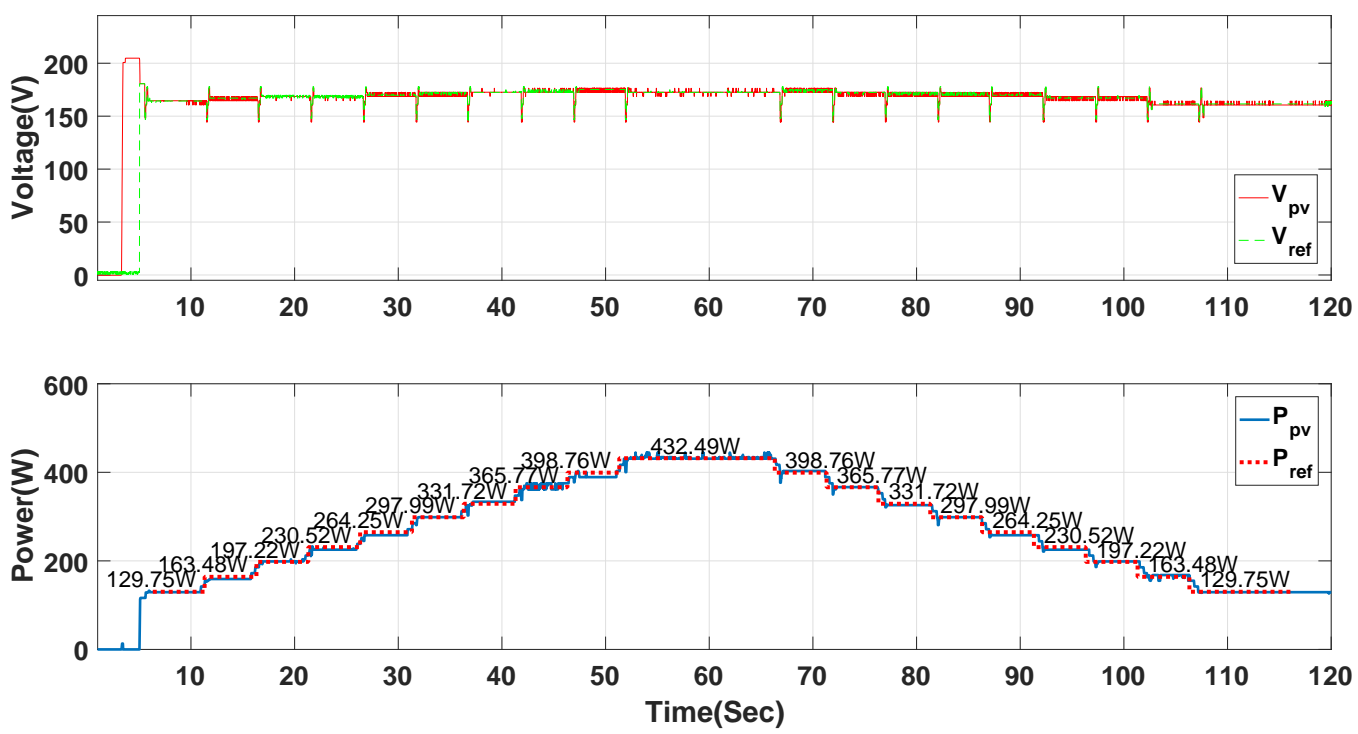

(d)

Figure 29. Experimental test of (a) P\&O; (b) INC; (c) GSS; (d) NQI.

As discussed in Section 3.3, the problems described in Figures 21 and 23 are due to the fact that the PV curve changes before the current MPP is reached. In other words, we can define the following:

$$
\tau_{s}=\frac{t_{p v}}{t_{\text {track }}}
$$

where $t_{p v}$ is the timescale of PV curve changes and $t_{\text {track }}$ is the time required by the MPPT controller to reach the MPP. If $\tau_{s} \leq 1$, then the problems in Figures 21 and 23 will occur. Otherwise, if $\tau_{s}>1$, the solution is guaranteed to converge to the MPP if the initial conditions and convergence criteria are well selected. The advantage of $P \& O$ and INC is that, even under the condition $\tau_{s} \leq 1$, they do not suffer from the problems of Figures 22 and 24, as shown in Figures 25 and 26. Table 2 summarizes the general characteristics of the four algorithms.

Table 2. Characteristics of the four DMPPT methods.

\begin{tabular}{cccccccc}
\hline & $\begin{array}{c}\text { Types } \\
\text { of } \\
\text { DMPPT }\end{array}$ & Initialization & $\begin{array}{c}\text { Effect of } \\
\text { Initialization } \\
\text { toward } \\
\text { Accuracy }\end{array}$ & $\begin{array}{c}\text { Survivability } \\
\text { under Rapid } \\
\text { Change of } \\
\text { Irradiance }\end{array}$ & $\begin{array}{c}\text { Transient } \\
\text { Fluctuation }\end{array}$ & FLOPs & $\begin{array}{c}\text { Convergence } \\
\text { Criteria }\end{array}$ \\
\hline P\&O & PBM & 1 & Not affecting & Excellent & Small & 11 & No required \\
\hline INC & CM & 1 & Not affecting & Excellent & Small & 11 & No required \\
\hline GSS & BBM & 2 & Affecting & Poor & Big & 11 & Required \\
\hline NQI & IBM & 3 & Affecting & Poor & Varies & 19 & Required \\
\hline
\end{tabular}

For DMPPT, it is good enough to use P\&O or INC if one is not aware of how the PV curves changes. They only require one IP, and do not require convergence criteria and simply repeat the update process continuously. Hence, they are quite robust algorithms and have better survivability under rapid changing. Nevertheless, their tracking speeds are not high if the perturbation size is selected to be very small as Figure 14 indicates. On the other hand, since GSS and NQI do not require any perturbation size, as discussed in Sections 2.3 and 2.4, the convergence speed can be fast as there is no need to select the perturbation step size. Hence, if the PV system is installed at a place where irradiance or temperature seldom change, one can use GSS for MPPT due to its fast convergence. 
The IPs for GSS, which require bracketing of the MPP are also not too difficult to set. For NQI, if $\tau_{s}>1$, and one is able to avoid the NQI trap by adding a checking scheme, then NQI can also achieve fast convergence. Finally, it is not recommended to use NQI if one is not aware of how the PV curves vary because of the NQI trap and other convergence problems mentioned in the paper are likely to occur.

\section{Conclusions}

This paper has provided a comprehensive review and discussion of four simple DMPPT algorithms. Moreover, problems faced by these algorithms from the perspective of initialization and convergence criteria are identified and addressed. In relation to initialization, NQI can suffer from the NQI trap, caused by two consecutive iterations, yielding similar maximum power point predictions. In relation to convergence criteria, GSS and NQI can converge to the wrong point, which is far away from MPP during rapid changes and never be able to escape even when the rapid changes stop. Hence, multi-particle DMMP algorithms like GSS and NQI have the ability to speed up the tracking process. However, they can cause the algorithm to misrecognize the best power point when rapid changes occur.

Author Contributions: The research was carried out successfully with contribution from all authors. The main research idea, case scenario studies, and the design of experimental setup were contributed by Kuo Lung Lian. Victor Andrean contributed to the implementation of simulation and experiment, and the analysis of these data. Pei Cheng Chang partially contributed to the implementation of the experiement and simulation. Victor Andrean and Kuo Lung Lian have mainly contributed to the preparation of the manuscript. All authors revised and approved the publication of the paper.

Funding: This work was financially supported by Connect Co. Ltd., Ministry of Science and Technology (MOST), Taiwan (under Grant No. 106-2221-E-011-100) and the Taiwan Building Technology Center from the Featured Areas Research Center Program within the framework of the Higher Education Sprout Project by the Ministry of Education in Taiwan.

Acknowledgments: The authors would like to sincerely thank the editor and anonymous reviewers for their valuable comments and suggestions, which improved the quality of the paper.

Conflicts of Interest: The authors declare no conflict of interest.

\section{Appendix A}

The "NQI trap" can be proven mathematically as follows. Consider

$$
\Delta i j=\frac{P_{j}-P_{i}}{V_{j}-V_{i}}
$$

The following derivation corresponds to Figure 17a.

1st iteration

By referring to Equation (8), we get

$$
V_{m p p}^{(i)}=\frac{1}{2}\left(\left(V_{1}+V_{2}\right)-\frac{\Delta_{12}}{\frac{\Delta_{23}-\Delta_{12}}{V_{3}-V_{1}}}\right),
$$

where $\Delta i j$ is defined as shown in (A1) and $P_{2}=P_{3}$ will result in $\Delta_{23}=0$. Therefore,

$$
V_{m p p}^{(i)}=\frac{1}{2}\left(V_{2}+V_{3}\right)=V_{m e} .
$$

\section{2nd iteration}

$$
V_{1}^{\prime}=V_{2}
$$




$$
\begin{gathered}
V_{2}^{\prime}=V_{m p p}^{(i)}=V_{m e} \\
V_{3}^{\prime}=V_{3} \\
V_{m p p}^{(i+1)}=\frac{1}{2}\left(V_{1}^{\prime}+V_{2}^{\prime}-\frac{\Delta_{12}^{\prime}}{\frac{\Delta_{23}^{\prime}-\Delta_{12}^{\prime}}{V_{3}^{\prime}-V_{1}^{\prime}}}\right)
\end{gathered}
$$

because $\Delta_{23}^{\prime}=-\Delta_{12}^{\prime}$

$$
\begin{gathered}
V_{m p p}^{(i+1)}=\frac{1}{2}\left(V_{1}^{\prime}+V_{2}^{\prime}-\frac{\Delta_{12}^{\prime}}{-\Delta_{12}^{\prime}-\Delta_{12}^{\prime}}\left(V_{3}^{\prime}-V_{1}^{\prime}\right)\right) \\
=\frac{1}{2}\left(\frac{1}{2}\left(V_{1}^{\prime}+V_{3}^{\prime}\right)+V_{2}^{\prime}\right) .
\end{gathered}
$$

From (A2), $\frac{1}{2}\left(V_{1}^{\prime}+V_{3}^{\prime}\right)=\frac{1}{2}\left(V_{2}+V_{3}\right)=V_{m e}$. Therefore,

$$
\begin{gathered}
V_{m p p}^{(i+1)}=\frac{1}{2}\left(V_{2}^{\prime}+V_{2}^{\prime}\right), \\
V_{m p p}^{(i+1)}=V_{2}^{\prime}=V_{m e} .
\end{gathered}
$$

From the 1st and 2nd iterations, we see that $V_{m p p}^{(i)}=V_{m p p}^{(i+1)}=V_{m e}$, which means that the two points are becoming singular.

The derivation below corresponds to Figure 17b.

1st iteration

$$
V_{m p p}^{(i)}=\frac{1}{2}\left(\left(V_{1}+V_{2}\right)-\frac{\Delta_{12}}{\frac{\Delta_{23}-\Delta_{12}}{V_{3}-V_{1}}}\right) .
$$

$P_{1}=P_{2}$ will result in $\Delta_{12}=0$. Therefore,

$$
V_{m p p}^{(i)}=\frac{1}{2}\left(V_{1}+V_{2}\right)=V_{m e}
$$

\section{2nd iteration}

$$
\begin{gathered}
V_{1}^{\prime}=V_{1}, \\
V_{2}^{\prime}=V_{m p p}^{(i)}, \\
V_{3}^{\prime}=V_{2} \\
=\frac{1}{2}\left(V_{1}^{\prime}+V_{2}^{\prime}-\frac{\Delta_{12}^{\prime}}{\frac{\Delta_{23}^{\prime}-\Delta_{12}^{\prime}}{V_{3}^{\prime}-V_{1}^{\prime}}}\right)
\end{gathered}
$$


because $\Delta_{23}^{\prime}=-\Delta_{12}^{\prime}$

$$
\begin{gathered}
V_{m p p}^{(i+1)}=\frac{1}{2}\left(V_{1}^{\prime}+V_{2}^{\prime}-\frac{\Delta_{12}^{\prime}}{-\Delta_{12}^{\prime}-\Delta_{12}^{\prime}}\left(V_{3}^{\prime}-V_{1}^{\prime}\right)\right) \\
=\frac{1}{2}\left(\frac{1}{2}\left(V_{1}^{\prime}+V_{3}^{\prime}\right)+V_{2}^{\prime}\right) .
\end{gathered}
$$

Because $\frac{1}{2}\left(V_{1}+V_{3}\right)=V_{2}$

$$
\begin{gathered}
V_{m p p}^{(i+1)}=\frac{1}{2}\left(V_{2}^{\prime}+V_{2}^{\prime}\right), \\
V_{m p p}^{(i+1)}=V_{2}^{\prime}=V_{m e} .
\end{gathered}
$$

From the 1st and 2nd iterations, we see that $V_{m p p}^{(1)}=V_{m p p}^{(i+1)}=V_{m e}$, which means that the two points are becoming singular.

\section{References}

1. McCrone, A.; Moslener, U.; d'Estais, F.; Gruning, C. Global Trends in Renewable Energy Investment 2017; Frankfurt School-UNEP Centre/BNEF: Frankfurt am Main, Germany, 6 April 2017; pp. 1-90.

2. International Energy Agency. Global trends in renewable energy investment 2017. In Tracking Clean Energy Progress 2017; International Energy Agency: Paris, France, 2017; pp. 1-112.

3. Teng, J.H.; Huang, W.H.; Hsu, T.A.; Wang, C.Y. Novel and Fast Maximum Power Point Tracking for Photovoltaic Generation. IEEE Trans. Ind. Electron. 2016, 63, 4955-4966. [CrossRef]

4. Pilawa-Podgurski, R.C.N.; Perreault, D.J. Sub-module integrated distributed maximum power point tracking for solar photovoltaic applications. In Proceedings of the IEEE Energy Conversion Congress and Exposition (ECCE), Raleigh, NC, USA, 5-20 September 2012; pp. 4776-4783.

5. Poshtkouhi, S.; Varley, J.; Popuri, R.; Trescases, O. Analysis of distributed peak power tracking in photovoltaic systems. In Proceedings of the 2010 International Power Electronics Conference-ECCE ASIA, Sapporo, Japan, 21-24 June 2010; pp. 942-947.

6. Luo, H.; Wen, H.; Li, X.; Jiang, L.; Hu, Y. Synchronous buck converter based low-cost and high-efficiency sub-module DMPPT PV system under partial shading conditions. Energy Convers. Manag. 2016, 126, $473-487$. [CrossRef]

7. Birane, M.; Larbes, C.; Cheknane, A. Comparative study and performance evaluation of central and distributed topologies of photovoltaic system. Int. J. Hydrog. Energy 2017, 42, 8703-8711. [CrossRef]

8. Poshtkouhi, S.; Palaniappan, V.; Fard, M.; Trescases, O. A General Approach for Quantifying the Benefit of Distributed Power Electronics for Fine Grained MPPT in Photovoltaic Applications Using 3-D Modeling. IEEE Trans. Power Electron. 2012, 27, 4656-4666. [CrossRef]

9. Amir, A.; Amir, A.; Selvaraj, J.; Rahim, N. Study of the MPP tracking algorithms: Focusing the numerical method techniques. Renew. Sustain. Energy Rev. 2016, 62, 350-371. [CrossRef]

10. Danandeh, M.A.; Mousavi, S.M.G. Comparative and comprehensive review of maximum power point tracking methods for PV cells. Renew. Sustain. Energy Rev. 2018, 82, 2743-2767. [CrossRef]

11. Eltawil, M.A.; Zhao, Z. MPPT techniques for photovoltaic applications. Renew. Sustain. Energy Rev. 2013, 25, 793-813. [CrossRef]

12. Bendib, B.; Belmili, H.; Krim, F. A survey of the most used MPPT methods: Conventional and advanced algorithms applied for photovoltaic systems. Renew. Sustain. Energy Rev. 2015, 45, 637-648. [CrossRef]

13. Subudhi, B.; Pradhan, R. A Comparative Study on Maximum Power Point Tracking Techniques for Photovoltaic Power Systems. IEEE Trans. Sustain. Energy 2013, 4, 89-98. [CrossRef] 
14. Kimball, J.W.; Krein, P.T. Discrete-Time Ripple Correlation Control for Maximum Power Point Tracking. IEEE Trans. Power Electron. 2008, 23, 2353-2362. [CrossRef]

15. Wasynezuk, O. Dynamic Behavior of a Class of Photovoltaic Power Systems. IEEE Trans. Power Appl. Syst. 1983, PAS-102, 3031-3037. [CrossRef]

16. Kjær, S.B. Evaluation of the Hill Climbing and Incremental Conductance Maximum Power Point Trackers for Photovoltaic Power Systems. IEEE Trans. Energy Convers. 2012, 27, 922-929. [CrossRef]

17. Samantara, S.; Roy, B.; Sharma, R.; Choudhury, S.; Jena, B. Modeling and simulation of integrated CUK converter for grid connected PV system with EPP MPPT hybridization. In Proceedings of the 2015 IEEE Power, Communication and Information Technology Conference (PCITC), Bhubaneswar, India, 15-17 October 2015; pp. 397-402. [CrossRef]

18. Ahmed, J.; Salam, Z. A Modified P O Maximum Power Point Tracking Method with Reduced Steady-State Oscillation and Improved Tracking Efficiency. IEEE Trans. Sustain. Energy 2016, 7, 1506-1515. [CrossRef]

19. Liu, F.; Duan, S.; Liu, F.; Liu, B.; Kang, Y. A Variable Step Size INC MPPT Method for PV Systems. IEEE Trans. Ind. Electron. 2008, 55, 2622-2628. [CrossRef]

20. Chu, C.C.; Chen, C.L. Robust maximum power point tracking method for photovoltaic cells: A sliding mode control approach. Sol. Energy 2009, 83, 1370-1378. [CrossRef]

21. Liu, Y.; Chen, L.; Chen, L.; Xin, H.; Gan, D. A newton quadratic interpolation based control strategy for photovoltaic system. In Proceedings of the International Conference on Sustainable Power Generation and Supply (SUPERGEN 2012), Hangzhou, China, 8-9 September 2012; pp. 1-6. [CrossRef]

22. Pai, F.S.; Chao, R.M.; Ko, S.H.; Lee, T.S. Performance Evaluation of Parabolic Prediction to Maximum Power Point Tracking for PV Array. IEEE Trans. Sustain. Energy 2011, 2, 60-68. [CrossRef]

23. Wang, P.; Zhu, H.; Shen, W.; Choo, F.H.; Loh, P.C.; Tan, K.K. A novel approach of maximizing energy harvesting in photovoltaic systems based on bisection search theorem. In Proceedings of the 2010 Twenty-Fifth Annual IEEE Applied Power Electronics Conference and Exposition (APEC), Palm Springs, CA, USA, 21-25 February 2010; pp. 2143-2148. [CrossRef]

24. Zhang, Q.; Hu, C.; Chen, L.; Amirahmadi, A.; Kutkut, N.; Shen, Z.J.; Batarseh, I. A Center Point Iteration MPPT Method with Application on the Frequency-Modulated LLC Microinverter. IEEE Trans. Power Electron. 2014, 29, 1262-1274. [CrossRef]

25. Chun, S.; Kwasinski, A. Analysis of Classical Root-Finding Methods Applied to Digital Maximum Power Point Tracking for Sustainable Photovoltaic Energy Generation. IEEE Trans. Power Electron. 2011, 26, 3730-3743. [CrossRef]

26. Hosseini, S.H.; Farakhor, A.; Haghighian, S.K. Novel algorithm of maximum power point tracking (MPPT) for variable speed PMSG wind generation systems through model predictive control. In Proceedings of the 2013 8th International Conference on Electrical and Electronics Engineering (ELECO), Bursa, Turkey, 28-30 November 2013; pp. 243-247. [CrossRef]

27. Xiao, W.; Dunford, W.G.; Palmer, P.R.; Capel, A. Application of Centered Differentiation and Steepest Descent to Maximum Power Point Tracking. IEEE Trans. Ind. Electron. 2007, 54, 2539-2549. [CrossRef]

28. Jamil, M.; Saeed, H.; Qaisar, S.; Felemban, E.A. Maximum power point tracking of a solar system using state space averaging for wireless sensor network. In Proceedings of the 2013 IEEE International Conference on Smart Instrumentation, Measurement and Applications (ICSIMA), Kuala Lumpur, Malaysia, 25-27 November 2013; pp. 1-6. [CrossRef]

29. Miyatake, M.; Veerachary, M.; Toriumi, F.; Fujii, N.; Ko, H. Maximum Power Point Tracking of Multiple Photovoltaic Arrays: A PSO Approach. IEEE Trans. Aerosp. Electron. Syst. 2011, 47, 367-380. [CrossRef]

30. Shao, R.; Wei, R.; Chang, L. A multi-stage MPPT algorithm for PV systems based on golden section search method. In Proceedings of the 2014 IEEE Applied Power Electronics Conference and Exposition-APEC 2014, Fort Worth, TX, USA, 16-20 March 2014; pp. 676-683. [CrossRef]

31. Kiefer, J. Sequential Minimax Search for a Maximum. Proc. Am. Math. Soc. 1953, 4, 502-506. [CrossRef]

32. Shao, R.; Chang, L. A new maximum power point tracking method for photovoltaic arrays using golden section search algorithm. In Proceedings of the 2008 Canadian Conference on Electrical and Computer Engineering, Niagara Falls, ON, Canada, 4-7 May 2008; pp. 000619-000622. [CrossRef]

33. Mathews, J.; Fink, K. Numerical Methods Using MATLAB; Featured Titles for Numerical Analysis Series; Pearson Prentice Hall: Upper Saddle River, NJ, USA, 2004. 
34. Ropp, M.E.; Gonzalez, S. Development of a MATLAB/Simulink Model of a Single-Phase Grid-Connected Photovoltaic System. IEEE Trans. Energy Convers. 2009, 24, 195-202. [CrossRef]

35. Kumar, N.; Hussain, I.; Singh, B.; Panigrahi, B.K. Self-Adaptive Incremental Conductance Algorithm for Swift and Ripple Free Maximum Power Harvesting from PV Array. IEEE Trans. Ind. Inf. 2018, 14, 2031-2041. [CrossRef]

36. Elgendy, M.A.; Zahawi, B.; Atkinson, D.J. Assessment of the Incremental Conductance Maximum Power Point Tracking Algorithm. IEEE Trans. Sustain. Energy 2013, 4, 108-117. [CrossRef]

37. Femia, N.; Petrone, G.; Spagnuolo, G.; Vitelli, M. Optimizing duty-cycle perturbation of P\&O MPPT technique. In Proceedings of the 2004 IEEE 35th Annual Power Electronics Specialists Conference (IEEE Cat. No. 04CH37551), Aachen, Germany, 20-25 June 2004; Volume 3, pp. 1939-1944. [CrossRef]

38. European Committee for Electrotechnical Standardization. Overall Efficiency of Grid Connected Photovoltaic Inverters; BSI: Brussels, Belgium, 2010.

(c) 2018 by the authors. Licensee MDPI, Basel, Switzerland. This article is an open access article distributed under the terms and conditions of the Creative Commons Attribution (CC BY) license (http://creativecommons.org/licenses/by/4.0/). 